\title{
Crisis del petróleo, transición a la democracia y frenazo de la expansión turística en España, 1973-1985*
}

\author{
Marta LuQue Aranda \\ Universidad de Málaga \\ martaluque@uma.es \\ Carmelo Pellejero Martínez \\ Universidad de Málaga \\ cpellejero@uma.es
}

Recibido: 03/02/2015

Aceptado: 07/06/2015

\section{RESUMEN}

El objetivo del presente trabajo es analizar los notables efectos que la crisis del petróleo de los años setenta y el final del crecimiento dorado de las economías occidentales, una coyuntura que en España tuvo el añadido de la transición política a la democracia, provocaron sobre las demandas turísticas nacional e internacional, por vez primera desde 1946 con tasas anuales de variación negativas; sobre el sector hotelero, seriamente afectado por problemas de capitalización; y sobre la política turística aplicada por los poderes públicos, bastante continuista y muy condicionada por los cambios institucionales impuestos por la Constitución aprobada en 1978.

Palabras clave: Petróleo, Crisis, Turismo, España, Siglo XX.

\section{The Oil Crisis, Transition to Democracy and the Slump in Spanish Tourism Growth, 1973-1985}

\begin{abstract}
The aim of this paper is to analyze the significant effects of the seventies oil crisis and the end of the Golden Age in Western economies at a time when Spain had the political transition process to democracy. These brought about: negative annual rates of change in national and international tourist supply and demand for the first time since 1946, serious capitalization problems in the hotel sector and a tourism policy applied by public authorities, which was influenced by and largely continued the institutional changes brought by the Constitution passed in 1978.
\end{abstract}

Key words: Oil, Crisis, Tourism, Spain, Twentieth Century.

\footnotetext{
*Este trabajo forma parte del proyecto de investigación HAR2011-23214, financiado por el Ministerio de Economía y Competitividad. Listado de abreviaturas: BOE (Boletín Oficial del Estado), OMT (Organización Mundial del Turismo), INE (Instituto Nacional de Estadística), MIT (Ministerio de Información y Turismo), MCT (Ministerio de Comercio y Turismo) y MTTC (Ministerio de Transporte, Turismo y Comunicaciones).
} 


\section{Introducción}

Fue en los años dorados del capitalismo cuando el turismo se transformó en España en un fenómeno de masas. A lo largo de los años cincuenta y sesenta, un periodo en el que fue creciente el número de ciudadanos de naciones occidentales dispuestos a emprender viajes de placer, nuestro país fue un destino cercano, barato, tranquilo, que ofreció a los viajeros un litoral generoso en buenas playas y horas de sol, y en el que sus gobernantes fueron poco a poco dejando atrás sus reticencias iniciales hacia el turismo y se fueron convenciendo de las innumerables bondades del mismo. Con estos atractivos no fue difícil que los grandes turoperadores turísticos fijaran su atención en España y que, por lo tanto, ésta se convirtiera en apenas dos décadas en uno de los destinos más demandados a nivel mundial. La mejor prueba del boom turístico español es que entre 1951 y 1973 el número de turistas extranjeros creció de 0 '7 a $31^{\prime} 6$ millones ${ }^{1}$.

El objetivo del presente trabajo es, precisamente, analizar cuándo, por qué y cómo finalizó este boom. Algo que ocurrió en la segunda mitad de la década de los años setenta, una etapa marcada por la crisis del petróleo y en España, además, por la transición a la democracia. En las siguientes páginas trataremos de explicar y cuantificar los efectos negativos que una coyuntura internacional y nacional tal adversa tuvo sobre la demanda y la oferta turísticas. Veremos que la llegada de turistas internacionales registró varios años, y por vez primera desde la finalización de la segunda guerra mundial, tasas negativas de variación, que los movimientos turísticos de los españoles también se resintieron, que el sector hotelero tuvo que hacer frente a serios problemas de descapitalización y que este escenario sólo comenzó a cambiar conforme fue avanzado la primera mitad de la década de los ochenta. Asimismo, comprobaremos que la crisis del petróleo fue un periodo caracterizado, pese a las crecientes críticas a la política turística aplicada hasta entonces y a sus consecuencias, por el carácter más o menos continuista de la misma y, también, por el creciente convencimiento de la necesidad de prestar más atención al concepto de sostenibilidad, por los cambios institucionales impuestos por la nueva Carta Magna y por una cierta dejación de funciones por parte de la Administración Central, incapaz de definir una estrategia turística nacional.

1 Para una visión general del boom turístico español véase BAYÓN, Fernando (Director): 50 años del turismo español, Madrid, Centro de Estudios Ramón Areces, 1999; CALS, Joan: Turismo y política turística en España: una aproximación, Barcelona, Ariel, 1974; ESTEVE SECALL, Rafael y FUENTES GARCÍA, Rafael: Economía, historia e instituciones del turismo en España, Madrid, Pirámide, 2000; FERNÁNDEZ FUSTER, Luis: Historia general del turismo de masas, Madrid, Alianza, 1991; MORENO GARRIDO, Ana: Historia del turismo en España en el siglo XX, Madrid, Síntesis, 2007; PACK, Sasha David: La invasión pacífica. Los turistas y la España de Franco, Madrid, Turner, 2009; PELLEJERO MARTÍNEZ, Carmelo (Director): Historia de la economía del turismo en España, Madrid, Civitas, 1999; VALLEJO POUSADA, Rafael: "Turismo y desarrollo económico en España durante el franquismo, 1939-1975", Revista de la Historia de la Economía y de la Empresa, VII, 2013, pp. 423-452; y VELASCO GONZÁLEZ, María: La política turística. Gobierno y administración turística en España (1952-2004), Valencia, Tirant lo Blanch, 2004. 


\section{Crisis del petróleo y transición política}

A lo largo de las décadas de los años cincuenta y sesenta, los denominados años dorados del capitalismo, las economías de los países desarrollados experimentaron un notable crecimiento de la producción, de la productividad, del empleo y del comercio. Fue un periodo caracterizado, además, por una gran estabilidad monetaria y cambiaria y por una importante mejora del nivel de bienestar de la población. Sin embargo, este panorama se vio bruscamente alterado en los primeros años de la década de 1970. Se inició entonces una nueva etapa, que se prologaría hasta mediados de la década de 1980, y en la que la economía mundial vivió momentos muy delicados, con considerables déficit públicos y preocupantes tasas de inflación y de desempleo, y en la que se impuso, sobre todo a partir de 1979, un nuevo modelo económico diametralmente opuesto al que se había aplicado en la edad de oro y que se basó, desde ese momento, en el libre mercado, el librecambio, la privatización y el abandono de las políticas fiscal y monetaria discrecionales. En definitiva, una nueva política económica enfocada a rebajar la intervención de los gobiernos mediante la desregulación, privatización y liberalización de los mercados ${ }^{2}$.

Una de las causas que propiciaron el fin del crecimiento dorado fue el colapso del sistema financiero internacional que había nacido en la reunión de Bretton Woods. Este sistema de tipos de cambio fijos y en el que el dólar, que definía su paridad en términos de oro y era convertible en este metal, era la divisa de reserva internacional, entró en crisis en 1971 cuando EEUU redujo la paridad de su moneda debido a su incapacidad para mantenerla dado su creciente desequilibrio exterior. El déficit exterior estadounidense y la pérdida de la relación fija entre oro y dólar provocaron que la liquidez internacional comenzara a crecer a ritmo alto y, sobre todo, no controlable. Algunos países, como Estados Unidos, Reino Unido y Japón, optaron por un sistema de tipos de cambio flotantes; otros, como la República Federal Alemana y Francia, trataron de mantener una zona de estabilidad cambiaria interna mediante un acuerdo por el que sus monedas debían mantenerse dentro de una bandas de fluctuación del $2 ’ 25 \%$ respecto a sus paridades. Pero lo cierto es que hasta la década de 1980 el predominio de los tipos de cambio flotantes favoreció los movimientos especulativos y provocó la inestabilidad de los mercados cambiarios.

El otro elemento decisivo para entender el cambio de rumbo experimentado por la economía mundial a inicios del decenio de 1970, y que incluso dio nombre a todo este periodo, fue la explosión del precio del petróleo en los últimos meses de 1973 a raíz de la guerra del Yom Kippur. Si en las décadas de 1950 y 1960 se pudo disponer de una energía barata, en la de los setenta ocurrió todo lo contrario. En la edad de oro el

2 Sobre las causas y efectos de la crisis del petróleo véase ALDCROFT, Derek H.: Historia de la economía europea, 1914-2000, Barcelona, Crítica, 2003; CARRERAS, Albert: "El siglo XX, entre rupturas y prosperidad (1914-2000)", en Antonio Di VITTORIO (Coord.), Historia económica de Europa. Siglos XV-XX, Barcelona, Crítica, 2003, pp. 381-397; COMÍN COMÍN, Francisco: Historia económica mundial. De los orígenes a la actualidad, Madrid, Alianza Editorial, 2011; MADDISON, Angus: La economía mundial, 1820-1992, Paris, OCDE, 1997; SEGURA, Julio: "La economía mundial entre 1973 y el siglo XXI: el final del crecimiento dorado", en Francisco COMÍN, Mauro HERNÁNDEZ y Enrique LLOPIS (Eds.), Historia económica mundial. Siglos X-XX, Barcelona, Crítica, 2005, pp. 391-432, VAN DER WEE, Herman: Prosperidad y crisis. Reconstrucción, crecimiento y cambio, 1945-1980, Barcelona, Crítica, 1986. 
precio del petróleo había sido bajo y estable, rondando los 1'7-1'9 dólares corrientes. Sin embargo, a finales de 1973 se produjo un fuerte encarecimiento de este input no sustituible y que se consumía muy alegremente en los países desarrollados. En dicho año y en el siguiente el precio del barril ascendió a 3'39 y 11'6 dólares, respectivamente. Y, lo que fue peor, desde entonces no dejó de crecer. De hecho, en 1978 el barril de petróleo costaba ya 14 dólares. Pero fue en 1979 y 1980, tras la revolución iraní y el inicio de la guerra entre Irak e Irán, cuando tuvo lugar la segunda gran subida del precio del oro negro, alcanzándose los 31' 6 y $36^{\prime} 8$ dólares, respectivamente. Este fue el punto de inflexión. Desde entonces se inició una suave caída que permitiría cerrar el año 1985 con un precio de $27^{\prime} 5$ dólares por barril ${ }^{3}$.

Las respuestas iniciales a la crisis de 1973 no fueron tampoco las más idóneas. Los gobiernos trataron de paliar los efectos de una traslación inmediata de la misma a los mercados y para ello incrementaron la oferta monetaria, los gastos públicos en sanidad, desempleo y jubilación, y las subvenciones a las empresas públicas y privadas afectadas. Asimismo, los sindicatos negociaron incrementos salariales que superaban la inflación, lo que provocó una espiral de crecimientos sucesivos de precios y salarios. Es decir, que la aplicación de las recetas keynesianas agravaron aún más los problemas económicos. Sin embargo, tras la subida del precio del petróleo en 1979, la respuesta de los gobiernos de los países desarrollados fue muy distinta. A partir de ese momento la nueva política económica tuvo como pilares básicos la lucha contra la inflación y los déficits presupuestario y exterior, una fiscalidad más eficiente y la reducción de la excesiva intervención y regulación característica de décadas anteriores. Esto último quedará plasmado reduciendo las barreras arancelarias, reformando los mercados de trabajo, liberalizando los mercados de capitales y de divisas, y privatizando algunas empresas públicas.

Las consecuencias económicas de la pérdida de la disciplina financiera internacional, del encarecimiento energético y de los vaivenes de la política económica fueron inmediatas, generalizadas y bastante graves. El PIB, que había crecido de manera sostenida en las economías occidentales a lo largo de más de dos décadas, experimentó tasas de variación negativas durante el bienio 1974-1975. Es cierto que a partir de 1976 las economías poderosas lograron crecer a tasas anuales que oscilaron entre el 3 y el 5 por ciento, pero la segunda gran subida del precio del carburante, aprobada en 1979, volvió a sumir a las mismas en un, en el mejor de los casos, grave estancamiento que se prolongó durante, al menos, tres años. En definitiva, la recuperación de la actividad productiva comenzó a hacerse realidad sólo a partir de $1983^{4}$.

\footnotetext{
3 Información referida a Arabian Light posted at Ras Tanura y recopilada en BP Statistical Review of World Energy, 2013, Historical data workbook. http://www.bp.com/en/global/corporate/about-bp/energy-economics/statistical-review-of-world-energy-2013.html

4 EUROPEAN COMMISSION: European economy, Belgium, European Communities, 2000.
} 


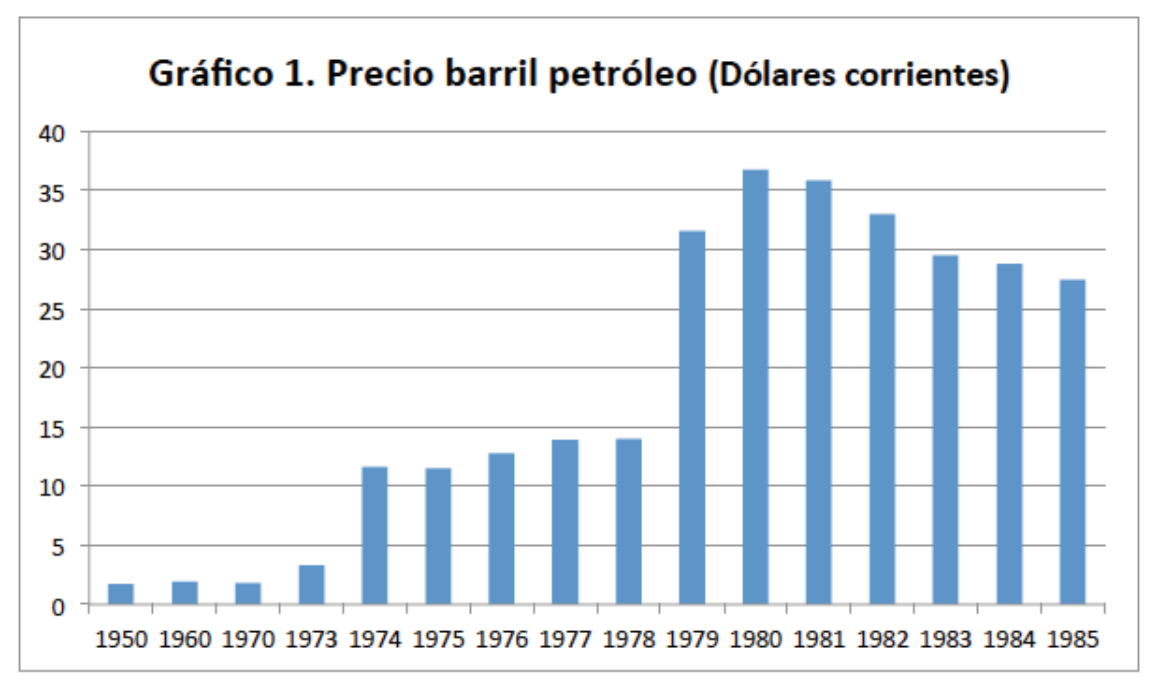

Fuente: BP Statistical Review of World Energy, 2013, Historical data workbook. http:// www.bp.com/en/global/corporate/about-bp/energy-economics/statistical-review-of-worldenergy-2013.html.

Además, la estabilidad de precios característica de los años dorados desapareció con el inicio de la década de 1970. El abandono de la relación fija entre el dólar y el oro por parte de EEUU en el verano de 1971, el enorme encarecimiento de la energía y la aplicación de las recetas keynesianas provocaron, sobre todo en la segunda mitad del decenio, unas tasas de inflación muy elevadas y desconocidas desde el final de la Segunda Guerra Mundial. Sólo a partir de 1981, y gracias a la nueva orientación de la política económica y a la caída del precio del crudo y de las materias primas, las economías comenzaron a reducirlas.

Por último, el retroceso de la actividad productiva y los precios disparados se vieron acompañados por un notable crecimiento de las tasas de paro. Las excepcionales oportunidades que habían conducido a una situación prácticamente de pleno empleo en el periodo 1950-1970 quedaron definitivamente atrás. En las economías occidentales el desempleo no dejó de crecer a lo largo de los años setenta e, incluso, en la primera mitad de los ochenta. Desgraciadamente, el cambio de rumbo experimentado por la política económica desde 1980, que permitió moderar la inflación y reactivar la economía, no tuvo el mismo éxito a la hora de reducir el paro. 


\begin{tabular}{|c|c|c|c|c|c|}
\hline Etapas & Alemania & Francia & G. Bretaña & EEUU & España \\
\hline $1961-1973$ & $4^{\prime} 4$ & $5^{\prime} 4$ & $3{ }^{\prime} 2$ & $4^{\prime} 4$ & $7^{\prime} 2$ \\
\hline $1974-1975$ & $-0^{\prime} 5$ & $1^{\prime} 4$ & $-1{ }^{\prime} 2$ & $-0^{\prime} 4$ & $3^{\prime} 0$ \\
\hline $1976-1979$ & $3^{\prime} 8$ & $3^{\prime} 5$ & $2^{\prime} 8$ & $4^{\prime} 8$ & $1^{\prime} 9$ \\
\hline $1980-1982$ & $0^{\prime} 1$ & $1^{\prime} 8$ & $-0^{\prime} 6$ & $0{ }^{\prime} 1$ & $0{ }^{\prime} 9$ \\
\hline $1983-1985$ & $2^{\prime} 2$ & $1^{\prime} 5$ & $3^{\prime} 3$ & $5^{\prime} 1$ & $2^{\prime} 1$ \\
\hline
\end{tabular}

Cuadro 1. PIB a precios de mercado de 1995. Tasas medias anuales de variación (\%). Fuente: EUROPEAN COMMISSION: European economy, Belgium, European Communities, 2000.

\begin{tabular}{|c|c|c|c|c|c|}
\hline Etapas & Alemania & Francia & G. Bretaña & EEUU & España \\
\hline $1961-1970$ & $2^{\prime} 7$ & $4^{\prime} 2$ & $3^{\prime} 9$ & $2^{\prime} 4$ & $5^{\prime} 8$ \\
\hline $1971-1973$ & $5^{\prime} 7$ & $6^{\prime} 6$ & $7^{\prime} 9$ & $4^{\prime} 4$ & $8^{\prime} 9$ \\
\hline $1974-1980$ & $4^{\prime} 7$ & $11^{\prime} 2$ & $15^{\prime} 7$ & $8^{\prime} 2$ & $17^{\prime} 8$ \\
\hline $1981-1985$ & $3^{\prime} 7$ & $9^{\prime} 5$ & $6^{\prime} 9$ & $5^{\prime} 2$ & $12^{\prime} 1$ \\
\hline
\end{tabular}

Cuadro 2. Inflación. Tasas medias anuales de variación (\%).

Fuente: EUROPEAN COMMISSION: European economy....

\begin{tabular}{|c|c|c|c|c|c|}
\hline Etapas & Alemania & Francia & G. Bretaña & EEUU & España \\
\hline $1961-1970$ & $0^{\prime} 7$ & $1^{\prime} 8$ & $1^{\prime} 7$ & $4^{\prime} 7$ & $2{ }^{\prime} 5$ \\
\hline $1971-1973$ & $0^{\prime} 7$ & $2^{\prime} 7$ & $2^{\prime} 6$ & $5^{\prime} 5$ & $2^{\prime} 9$ \\
\hline $1974-1979$ & $2^{\prime} 9$ & $4^{\prime} 5$ & $4^{\prime} 1$ & $6^{\prime} 8$ & $5^{\prime} 6$ \\
\hline $1980-1985$ & $5^{\prime} 6$ & $8^{\prime} 2$ & $9^{\prime} 7$ & $8^{\prime} 1$ & $16^{\prime} 9$ \\
\hline
\end{tabular}

Cuadro 3. Desempleo. Tasas medias anuales (\%). Fuente: EUROPEAN COMMISSION: European economy....

Como es natural, España no quedó al margen de la crisis económica ${ }^{5}$. Es más, los efectos fueron especialmente negativos y duraderos en nuestro país. Sobre todo, en términos de inflación y desempleo. En ello tuvo mucho que ver que el desarrollo de

5 Sobre la crisis en España véase, entre otros, CARRERAS, Albert y TAFUNELL, Xavier: Historia económica de la España contemporánea (1789-2009), Barcelona, Crítica, 2010; GARCÍA DELGADO, José Luis y JIMÉNEZ, Juan Carlos: "La economía", en La transición a la democracia y la España de Juan Carlos I, Madrid, Espasa-Calpe, 2003, Tomo XLII de la Historia de España Menéndez Pidal, pp. 379-429; ROJO, Luis Ángel: "La economía española en la democracia (1976-2000)", en Francisco COMÍN, Mauro HERNÁNDEZ y Enrique LLOPIS (Eds.), Historia económica de España. Siglos X-XX, Barcelona, Crítica, 2002, pp. 397-436; SEGURA, Julio: "La economía mundial entre 1973 y el siglo XXI: el final del crecimiento dorado", en Francisco COMÍN, Mauro HERNÁNDEZ y Enrique LLOPIS (Eds.), Historia económica mundial. Siglos X-XX, Barcelona, Crítica, 2005, pp. 391-432; y SERRANO SANZ, José María: "La crisis del petróleo", en Antoni FURIÓ et al, Las crisis a lo largo de la historia, Valladolid, Universidad de Valladolid, 2010, pp. 155-191. 
la crisis del petróleo coincidiera en España con la transición política a la democracia. No hay que olvidar que cuando los precios del oro negro se dispararon por vez primera a finales de 1973, España era una dictadura rechazada políticamente en Europa. Sin embargo, cuando en 1985 comenzó a materializarse el final de la crisis, nuestro país era una democracia admitida en la Comunidad Económica Europea. Es decir, que el marco político inicial y los objetivos de la ciudadanía española fueron distintos que los de las restantes economías europeas.

Para un país que en 1973 importaba casi el 80 por ciento de la energía utilizada para usos comerciales, que contaba con una elevada concentración en sectores industriales tradicionales intensivos en energía y que no se caracterizaba por un uso eficiente de la misma, tener que hacer frente a una factura energética mucho más cara no resultó nada fácil. Buena prueba de ello es que la inflación, del 8 por ciento en 1972, no paró de crecer hasta el año 1977 , cuando la tasa fue del $24^{\prime} 5$ por ciento ${ }^{6}$. Claro que, tal y como ocurrió en otras economías occidentales, la culpa no fue exclusiva del encarecimiento del petróleo. El aumento del gasto social, los altos incrementos salariales y el mantenimiento de los precios de los productos derivados del crudo hasta finales de 1975, también contribuyeron a la espiral inflacionista.

Precios descontrolados y, también, desempleo creciente y una actividad económica muy ralentizada. Al igual que la inflación, el paro tampoco dejó de aumentar año tras año. De una tasa del 2' 8 por ciento en 1973, a otra del 5'7 por ciento cuatro años después ${ }^{7}$. Por otro lado, en ese mismo periodo de tiempo, el PIB apenas creció a una tasa media anual del 3 por ciento ${ }^{8}$. Era urgente, pues, cambiar, una vez que la democracia había sido restaurada, la política económica. El primer paso en ese sentido se dio a finales de 1977 con la firma, por partidos políticos y agentes sociales, de los Pactos de la Moncloa. Desde ese momento la preocupación fundamental fue el control de la inflación y, en ese sentido, se devaluó la peseta, se contuvieron los salarios y se practicó una política monetaria más restrictiva. Unas medidas que provocaron una éxito indudable en el control de los precios, cayendo la tasa de inflación hasta el $14^{\prime} 4$ por ciento en $1982^{9}$, pero lamentablemente nulo sobre la actividad y el empleo. En el primer caso, en los cinco años siguientes a la aprobación de los Pactos, hubo tres donde el crecimiento del PIB apenas rondó el 1'5 por ciento anual y dos, 1979 y 1981 , donde las tasas fueron del 0 y del -0 '2 por ciento $^{10}$. Y en cuanto al desempleo, siguió con su preocupante escalada hasta alcanzar el $16^{\prime} 6$ por ciento en $1982^{11}$. Nada menos que seis puntos por encima de la tasa de paro de G. Bretaña, el doble que las de Francia e Italia y casi el triple que la de Alemania ${ }^{12}$.

Durante el primer gobierno socialista se realizó la reconversión industrial, se reformó parcialmente el mercado de trabajo, volvió a depreciarse la peseta, la política

\footnotetext{
6 CARRERAS, Albert y TAFUNELL, Xavier: Historia económica....

7 NICOLAU, Roser: "Población, salud y actividad", en Albert CARRERAS y Xavier TAFUNELL (Coords.), Estadísticas Históricas de España, Vol. I, Bilbao, Fundación BBVA, 2005, pp. 77-154.

8 EUROPEAN COMMISSION: European....

9 CARRERAS, Albert y TAFUNELL, Xavier: Historia económica....

10 EUROPEAN COMMISSION: European....

11 NICOLAU, Roser: "Población, salud.....

12 EUROPEAN COMMISSION: European economy....
} 
monetaria se hizo más restrictiva, se introdujo un sistema fiscal moderno, aumentaron los gastos sociales protectores, se inició el proceso de privatizaciones de empresas públicas, se avanzó notablemente en el Estado de bienestar y se preparó y liberalizó la economía española de cara al cumplimiento de las directivas de la Comunidad Económica Europea. Y, de nuevo, las consecuencias más positivas de esta política económica se dejaron sentir, gracias, también, al descenso del precio del crudo, en la lucha contra la inflación. En 1985 la tasa fue del 8'8 por ciento, muy similar a la de 1972 y la más baja desde entonces ${ }^{13}$. En cambio, el desempleo continuó año tras año acumulando records, registrándose en 1985 la tasa máxima del periodo, el 21'5 por ciento ${ }^{14}$, mientras que la actividad económica experimentó una tímida pero cierta reactivación, cifrada en unas tasas de crecimiento del PIB que oscilaron entre el 1'5 y el $2^{\prime} 6$ por ciento ${ }^{15}$.

Sin embargo, en la segunda mitad de la década la economía española sí vivió una fuerte expansión. En un contexto marcado por la recuperación de la economía mundial, el abaratamiento del precio del petróleo y la plena incorporación de España a la Comunidad Económica Europea, se moderaron aún más las tensiones inflacionistas, oscilando la tasa a finales de los noventa entre el 5 y el 6' 5 por ciento, se crearon cuatro millones de puestos de trabajo, lo que ayudó a que la tasa de paro se redujera en cinco puntos porcentuales, y el PIB creció a una tasa media del 4'2 por ciento.

\section{Crecimiento cíclico de la demanda turística internacional}

¿Cómo afectó a las actividades turísticas la grave crisis del petróleo? Según la Organización Mundial del Turismo, los viajes de placer, que habían experimentado desde finales de la Segunda Guerra Mundial un crecimiento sin precedentes, posibilitado por la bonanza económica, la generalización de las vacaciones pagadas, el aumento del tiempo libre y los notables avances en los transportes, no sufrieron demasiado durante la crisis del petróleo. A pesar de las dificultades económicas y del encarecimiento del transporte, los ciudadanos no renunciaron de manera significativa a viajar. De hecho, sólo hubo un año, concretamente 1982, en la que la tasa de variación del flujo turístico internacional fue negativa ${ }^{16}$. Pero lo que sí es indudable es que las llegadas internacionales de turistas, que habían crecido en el decenio de 1960 a una tasa anual media del 8'7 por ciento, ya no volvieron a hacerlo a ese ritmo. Sobre todo en los años inmediatamente posteriores a las dos bruscas subidas del precio del petróleo. Es decir, en los trienios 1974-1976 y 1980-1982, etapas en las que las citadas tasas fueron del 5 y del 1'1 por ciento, respectivamente.

Parece, pues, que en las sociedades occidentales el consumo turístico ofreció una notable resistencia a la baja a partir de ciertos niveles de renta. Para los ciudadanos con rentas altas, medias e, incluso, media-bajas, el turismo fue más un bien de primera necesidad que de lujo. La mayoría de ellos siguieron viajando. Pero, naturalmente,

\footnotetext{
13 CARRERAS, Albert y TAFUNELL, Xavier: Historia económica....

14 NICOLAU, Roser: "Población, salud....

15 EUROPEAN COMMISSION: European...

16 OMT: Estudio económico del turismo mundial, 1986 y OMT: Tourism Market Trends, 2006.
} 
durante la crisis la regularidad en el comportamiento de la demanda fue acompañada de importantes transformaciones en la elección de los destinos y en los medios de transporte utilizados. Ganaron terreno los destinos turísticos más cercanos y el transporte por carretera, especialmente el realizado en autobús.

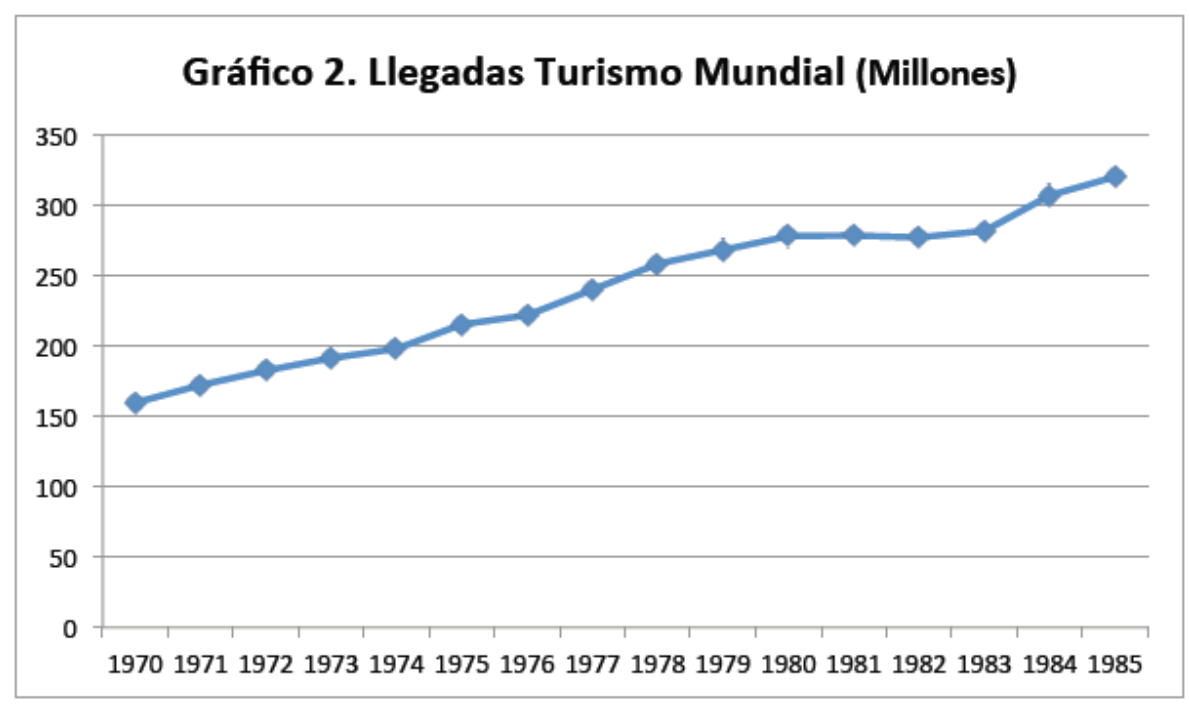

Fuente: OMT: Estudio económico del turismo mundial, 1986, y OMT: Tourism Market Trends, 2006.

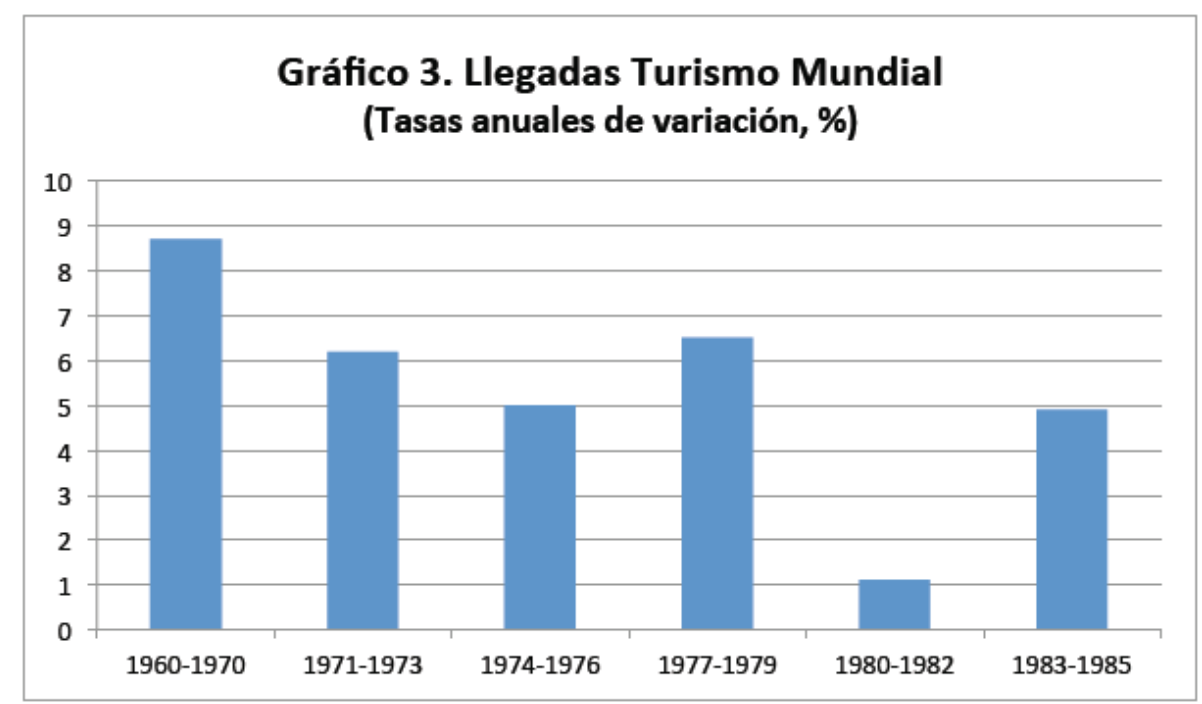

Fuente: OMT: Estudio económico... y OMT: Tourism Market... Elaboración propia. 
En España, no obstante, el impacto sobre el turismo fue algo mayor. El boom turístico que el país había venido experimentado desde la finalización de la Segunda Guerra Mundial se truncó en 1974. A lo largo de los años dorados del capitalismo España había sido muy atractiva para los grandes turoperadores turísticos por ser un destino cercano geográficamente a los principales países europeos emisores de turistas, que ofertaba un sinfín de playas y de horas de sol y que, además, siempre destacó por sus precios económicos. No hay que olvidar las dos devaluaciones de la peseta, en 1959 y 1967, y el deseo permanente de las autoridades españolas de ofertar unos precios turísticos bajos con la intención de captar al mayor número posible de turistas. Todo ello posibilitó, en un contexto internacional caracterizado por la trasformación del turismo en un fenómeno de masas, que entre 1951 y 1973 el número de turistas creciera en España a una tasa anual cercana al 19 por ciento y que en ningún año la tasa de variación fuera negativa.

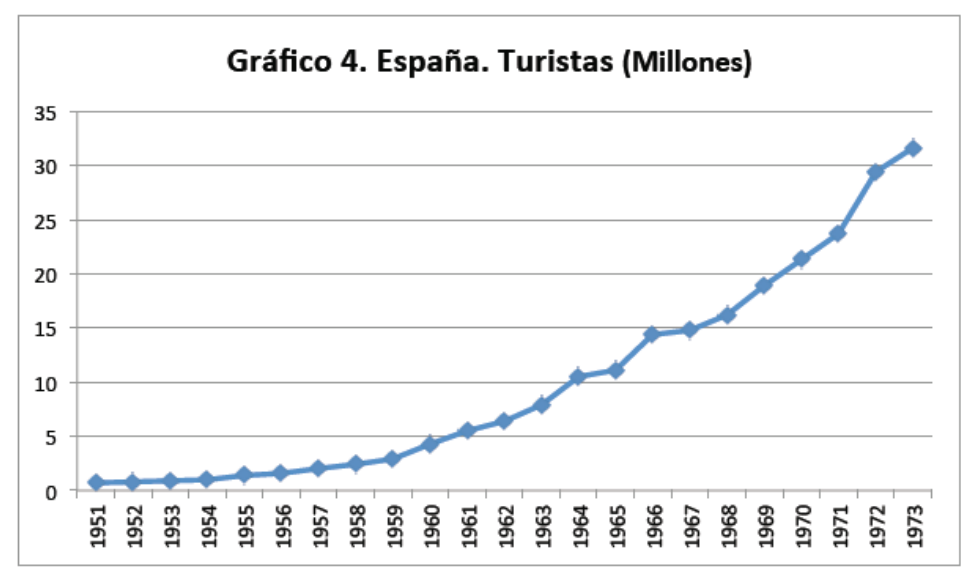

Fuente: MIT: Anuario de Estadísticas de Turismo, Madrid, 1963-1976.

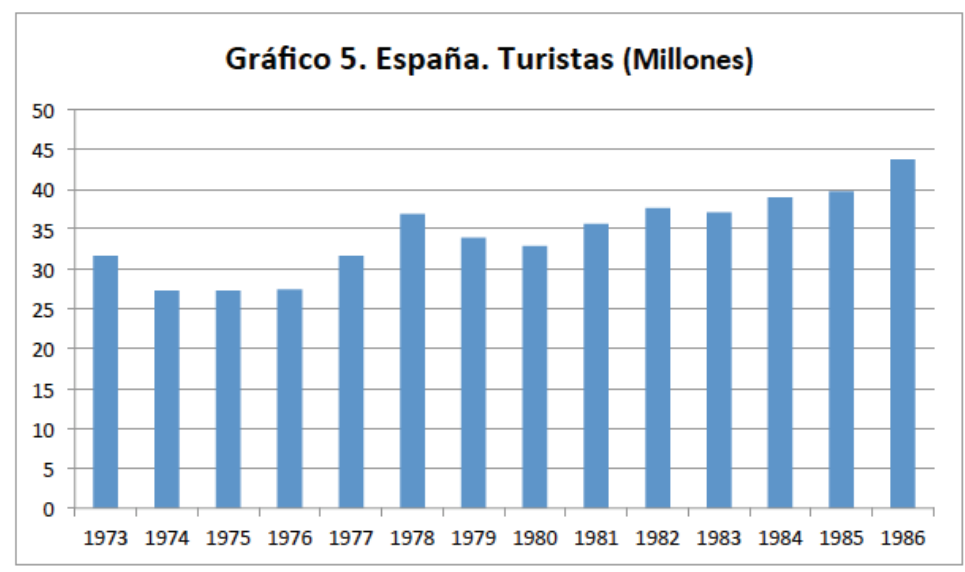

Fuente: MCT: Anuario de Estadísticas de Turismo, Madrid, 1977-1978, MIT: Anuario...., y MTTC: Anuario de Estadísticas de Turismo, Madrid, 1979-1989. 
Sin embargo, 1974 fue el primer año en el que el número de turistas no fue superior al del precedente. Llegaron 27'3 millones, 4'3 millones menos que la temporada anterior. Además, en los dos años siguientes las llegadas se estancaron. Consecuentemente, y aunque los ingresos nominales por turismo siguieron creciendo, los reales se redujeron ostensiblemente: en el trienio las tasas anuales de variación fueron de $-14^{\prime} 0,-3^{\prime} 6$ y $-5^{\prime} 5$ por ciento, respectivamente. No es de extrañar habida cuenta las dificultades económicas que atravesaron los países de nuestro entorno, el encarecimiento del transporte, la enorme cuota de mercado que los turistas de clases media y trabajadora, precisamente las más afectadas por la crisis y el paro, tenían en nuestro país y las quiebras a lo largo de 1974 de algunos turoperadores que operaban en España, como el noruego Mey Air, el finlandés Spear Tour y, sobre todo, el británico Court Line ${ }^{17}$. Asimismo, tampoco ayudó que España tuviera una inflación desbocada, 17 por ciento en 1976, que su gobierno fuera objeto de una dura campaña internacional tras las ejecuciones del mes de septiembre de 1975 y que el clima político fuera bastante inestable a raíz del creciente terrorismo, la muerte de Franco y la incertidumbre ante el proceso de transición a la democracia.

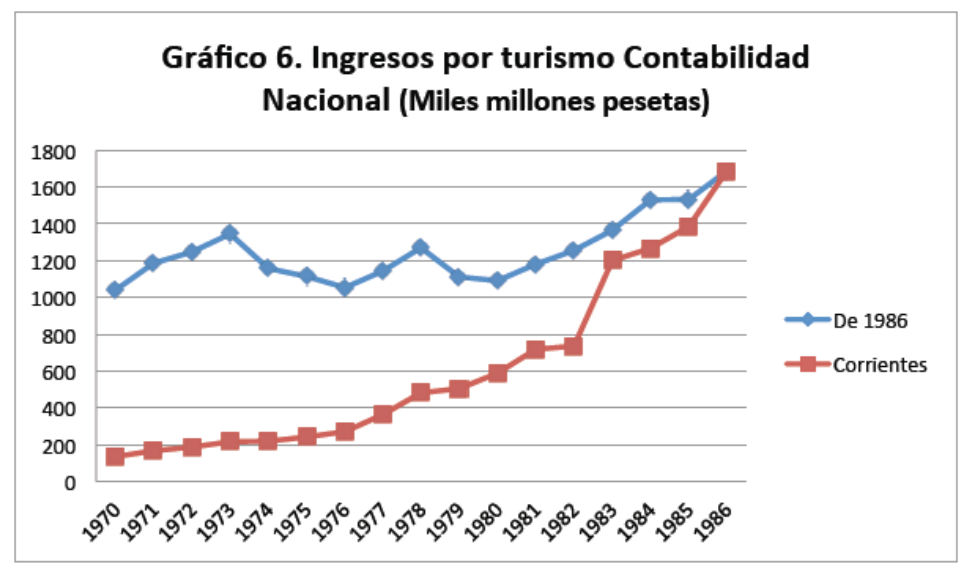

Fuente: TENA, Antonio: "Sector exterior", en Albert CARRERAS y Xavier TAFUNELL (Coords.), Estadísticas Históricas de España. Siglos XIX-XX, Vol. II, Bilbao, Fundación BBVA, 2005, pp. 573-644. Elaboración propia.

Tras este trienio complicado, y en el que muchos tomaron conciencia por primera vez de que el turismo no era una fuente inagotable, llegaron dos temporadas bastante buenas. En 1977 las llegadas aumentaron en cuatro millones, con lo que se recuperó el nivel previo a la crisis. Y al año siguiente se estableció un record histórico al visitarnos 37 millones de turistas. Además, en 1978 los ingresos reales por turismo superaron en un 20 por ciento los registrados dos años antes. En definitiva, una notable recuperación del sector propiciada, sobre todo, por la reactivación de la economía

17 GAVIRIA, Mario: El escándalo Court Line, Cuadernos para el diálogo, 57, Madrid, Edicusa, 1975, y VASALLO TOMÉ, Ignacio: “Crisis y consolidación, 1972-1982”, en Fernando BAYÓN MARINÉ (Director), 50 años del turismo español, Madrid, Cetro de Estudios Ramón Areces, 1999, pp. 105-124. 
internacional, el ligero declive del precio real del petróleo, una cierta estabilidad política interna tras la celebración de las primeras elecciones democráticas y, cómo no, las devaluaciones de la peseta aprobadas en febrero de 1976 y julio de 1977, que abarataron nuestra divisa frente al dólar en un 11 y un $24^{\prime} 9$ por ciento, respectivamente.

Pero la alegría duró poco. En el bienio 1979-1980 las tasas de variación anuales del movimiento turístico volvieron a ser negativas. De hecho, en este último año, y en comparación con 1978, llegaron a España cuatro millones de turistas menos y los ingresos reales por turismo fueron un 14 por ciento inferiores. Algo nada extraño teniendo en cuenta el estancamiento económico de las principales economías occidentales tras la nueva explosión del precio del crudo, la consiguiente elevación del precio del transporte, la tipología económica y laboral de la mayor parte de nuestros clientes y el encarecimiento de los hoteles españoles tras la liberalización de los precios turísticos aprobada en 1977 y que acabó con casi cuatro décadas en las que el Estado se había reservado el derecho a fijarlos.

El último ciclo, y en este caso, de nuevo, positivo, se inició en 1981. Desde ese ejercicio las llegadas de turistas mostraron una tendencia claramente creciente, aumentando en el sexenio siguiente a una tasa anual media del 4'8 por ciento y permitiendo cerrar el año 1986 con el record histórico registrado hasta ese momento: 43'7 millones de turistas. Paralelamente, los ingresos nominales y reales por turismo crecieron a unas tasas anuales medias del 19'1 y 7'5 por ciento, respectivamente. En definitiva, una etapa de notable expansión de los movimientos turísticos hacia España beneficiada por el creciente dinamismo de la economía internacional y por el continuo abaratamiento del barril de petróleo. Y, a nivel interno, por la devaluación de la peseta, aprobada en diciembre de 1982, y por el indudable éxito cosechado en nuestro país en el control de la inflación, lográndose en 1986 una tasa todavía bastante elevada, del 8' 8 por ciento, pero siete puntos porcentuales menor de la que se había registrado en 1980.

En cuanto a los medios de transporte utilizados por los turistas para visitar nuestro país, el más negativamente afectado durante la crisis del petróleo fue precisamente el preferido por la mayoría: la carretera. De hecho, durante el trienio siguiente al primer shock del precio del oro negro la media anual de turistas que optaron por ese medio fue de 17 millones, tres menos de la registrada en los dos años previos a la subida. En cambio, en el resto de opciones las consecuencias fueron prácticamente insignificantes. Asimismo, tras la subida de 1979 volvió a ser de nuevo la carretera el medio de transporte con mayor pérdida de usuarios. Por lo tanto, esto corrobora la idea de que la crisis económica y un transporte más caro no desalentaron demasiado a los turistas con mayor poder adquisitivo, los que empleaban el avión, y, por el contrario, si lo hicieron con aquellos que llegaban a España en automóvil o autobús, es decir, clientes, en principio, con menos recursos económicos y que, además, tuvieron que hacer frente a una gasolina más cara.

Por otro lado, hay que señalar que tras la vuelta a la normalidad, el número de turistas llegados por carretera siguió creciendo en términos absolutos pero no en términos relativos. Entre 1981 y 1986 su cuota porcentual cayó del 66 al 62 por ciento. Por el contrario, la correspondiente a los que aterrizaban en los aeropuertos españoles aumentó del 27 a casi el 32 por ciento. En definitiva, el avión fue el único medio de 
transporte que de manera significativa ganó cuota de mercado en la primera mitad de los ochenta y, como es lógico, en ello tuvo mucho que ver el declinante precio del petróleo.

\begin{tabular}{|c|c|c|c|c|}
\hline Periodo & Ferrocarril & Carretera & Puerto & Aeropuerto \\
\hline $1972-1973$ & 1,6 & 20,3 & 0,6 & 8,1 \\
\hline $1974-1976$ & 1,6 & 17,1 & 0,6 & 8,1 \\
\hline $1977-1978$ & 1,8 & 22,6 & 0,6 & 9,2 \\
\hline $1979-1980$ & 1,7 & 21,9 & 0,6 & 9,2 \\
\hline $1981-1983$ & 2,0 & 23,6 & 0,6 & 10,6 \\
\hline $1984-1986$ & 2,3 & 24,8 & 0,6 & 13,1 \\
\hline
\end{tabular}

Cuadro 4. España. Turistas por medio de transporte. Media anual en cada periodo (Millones). Fuente: MCT: Anuario...., MIT: Anuario..., y MTTC: Anuario.... Elaboración propia.

\begin{tabular}{|c|c|c|c|c|}
\hline Periodo & Ferrocarril & Carretera & Puerto & Aeropuerto \\
\hline $1972-1973$ & 5,0 & 66,5 & 1,9 & 26,6 \\
\hline $1974-1976$ & 5,7 & 62,6 & 2,1 & 29,6 \\
\hline $1977-1978$ & 5,4 & 66,0 & 1,7 & 26,9 \\
\hline $1979-1980$ & 5,1 & 65,6 & 1,6 & 27,7 \\
\hline $1981-1983$ & 5,4 & 64,1 & 1,7 & 28,8 \\
\hline $1984-1986$ & 5,7 & 60,7 & 1,5 & 32,1 \\
\hline
\end{tabular}

Cuadro 5. España. Turistas por medio de transporte. Cuotas relativas medias en cada periodo (\%). Fuente: MCT: Anuario..., MIT: Anuario..., y MTTC: Anuario.... Elaboración propia.

Por mercados, el comportamiento de los cuatro grandes emisores de turistas hacia España fue bastante diferente. Mientras que los ciclos negativos apenas afectaron a los mercados alemán y portugués, sí lo hicieron con el británico y, sobre todo, con el francés. En el trienio 1974-1976 las medias anuales de turistas galos y británicos que nos visitaron fueron, respectivamente, un 20'7 y un 17' 1 por ciento menores que en el bienio previo. Posteriormente, en el ciclo 1979-1980, mientras que los mercados luso, alemán y británico apenas se vieron afectados, el francés se redujo, de nuevo, notablemente. Su media anual de turistas, muy similar a la del periodo 1974-1976, fue 1'5 millones inferior a la del bienio 1977-1978.

En la década de los ochenta el mayor ritmo de crecimiento correspondió al mercado británico. Gracias su ello su cuota de mercado rondaba en 1986 el 14 por ciento, muy similar a la del mercado alemán y seis puntos porcentuales inferior a la del luso. El mercado francés, por el contrario, siguió también en esta etapa perdiendo importancia en España. Por lo tanto, su peso relativo, siempre el más elevado no obstante, mostró a lo largo de la crisis del petróleo una tendencia claramente decreciente, cayendo entre 1970 y 1986 del 40'8 al 25'6 por ciento, respectivamente. 


\begin{tabular}{|c|c|c|c|c|}
\hline Periodo & Alemania & Francia & G. Bretaña & Portugal \\
\hline $1972-1973$ & 3,3 & 11,6 & 3,5 & 4,4 \\
\hline $1974-1976$ & 3,8 & 9,2 & 2,9 & 4,1 \\
\hline $1977-1978$ & 4,7 & 11,2 & 3,0 & 6,8 \\
\hline $1979-1980$ & 4,6 & 9,7 & 3,3 & 7,4 \\
\hline $1981-1983$ & 4,7 & 10,5 & 4,6 & 7,8 \\
\hline $1984-1986$ & 5,5 & 10,7 & 5,7 & 8,1 \\
\hline
\end{tabular}

Cuadro 6. España. Turistas por nacionalidad. Media anual en cada periodo (Millones). Fuente: MCT: Anuario...., MIT: Anuario...., y MTTC: Anuario....Elaboración propia.

\begin{tabular}{|c|c|c|c|c|}
\hline Periodo & Alemania & Francia & G. Bretaña & Portugal \\
\hline $1972-1973$ & 10,8 & 37,8 & 11,3 & 14,2 \\
\hline $1974-1976$ & 13,9 & 33,7 & 10,8 & 15,1 \\
\hline $1977-1978$ & 13,7 & 32,7 & 8,9 & 19,8 \\
\hline $1979-1980$ & 13,7 & 29,2 & 10,0 & 22,3 \\
\hline $1981-1983$ & 12,7 & 28,6 & 12,4 & 21,3 \\
\hline $1984-1986$ & 13,5 & 26,2 & 13,9 & 19,8 \\
\hline
\end{tabular}

Cuadro 7. España. Turistas por nacionalidad. Cuotas relativas medias en cada periodo (\%). Fuente: MCT: Anuario...., MIT: Anuario..., y MTTC: Anuario.... Elaboración propia.

\section{Movimiento hotelero}

Cómo es lógico, durante la crisis del petróleo también se vio afectado el turismo nacional. La única manera de analizar cómo evolucionó dicho mercado a nivel interno es analizando las estadísticas elaboradas por el Instituto Nacional de Estadística sobre el movimiento de viajeros en establecimientos hoteleros. Es cierto que todos los clientes de los hoteles no son turistas. Y, también, que todos los turistas no se alojan en hoteles. Pero esta fuente nos permite hacernos una idea bastante aproximada de cómo respondieron la clientela nacional, y también la foránea, a lo largo del periodo analizado.

Desde 1966, primer año del que se disponen de datos estadísticos, hasta 1972 las estancias en los establecimientos hoteleros españoles habían aumentado a una tasa media anual del 13'4 por ciento. Sin embargo, tras el primer shock del precio del petróleo, las pernoctaciones mostraron una tendencia decreciente. Entre 1974 y 1976 la tasa anual media de variación fue de -1'5 por ciento. Pero en esa coyuntura el comportamiento de los mercados nacional e internacional fue completamente diferente. El foráneo, que había comenzado su declive desde el mismo año 1973, tocó fondo en 1976, cuando aportó un 20 por ciento de estancias menos que cuatro años antes. En cambio, la tendencia del mercado nacional fue la opuesta, aumentado las pernoc- 
taciones a una tasa anual media del 6' 6 por ciento. Un comportamiento por lo tanto muy dispar y que en buena parte se explica por las campañas de promoción que ante la reducción de la clientela extranjera llevaron a cabo los turoperadores para captar el mercado nacional y por la política compensatoria aplicada por las autoridades españolas para tratar de diferir el impacto petrolífero y ganar tiempo, empleando para ello las divisas acumuladas en los años previos y, posteriormente, amplias concesiones salariales y subvenciones al consumo de los productos energéticos.

Por el contrario, los excelentes resultados del bienio 1977-1978 se apoyaron, básicamente, en el mercado extranjero. Fueron dos ejercicios con cifras record. De hecho, los 121'4 millones de estancias totales registrados en 1978 no se superarían hasta el año 1984. Una recuperación del sector, pues, muy notable y en la que el papel primordial lo desempeñó la clientela foránea, muy animada por la devaluación de la peseta. En dos años se ganaron casi 21 millones de pernoctaciones. Por el contrario, el mercado nacional, muy activo todavía en 1977, con un crecimiento del 13 por ciento, ya comenzó a mostrar síntomas de retraimiento en 1978, cuando la tasa de variación fue del -8 por ciento. Parece, pues, que el aumento del desempleo y el encarecimiento de nuestros hoteles comenzaron a frenar ya a la clientela española.

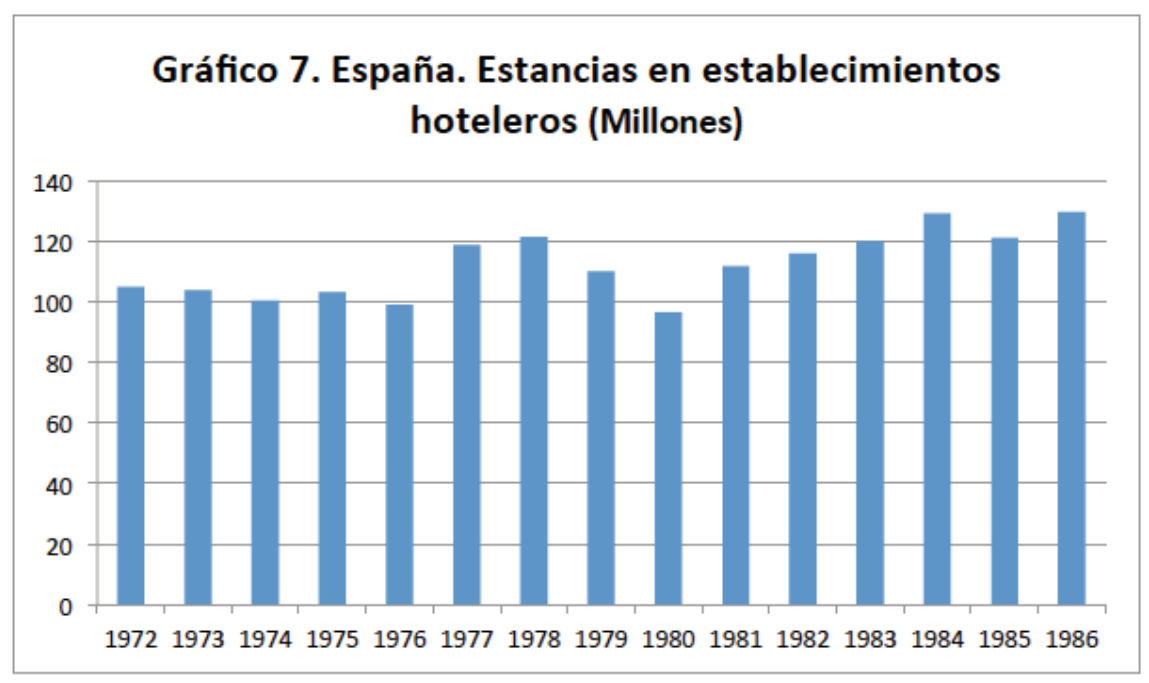

Fuente: INE: Estadística de turismo. Viajeros en hoteles y acampamentos, Madrid, 1973, INE: Viajeros en hoteles y acampamentos, Madrid, 1974-1977, e INE: Movimiento de viajeros en establecimientos turísticos, Madrid, 1978-1990.

En el bienio 1979-1980, y a raíz del impacto económico y social derivado de la segunda subida del precio del petróleo, el sector hotelero español volvió a verse muy afectado. La tasa de variación media anual de las estancias fue de casi el -11 por ciento, de tal manera que los resultados de 1980 fueron incluso más bajos que los de 1976. Hubo 25 millones menos de pernoctaciones que en el año record de 1978. Y aunque la evolución fue decreciente en ambos mercados, el peor parado fue el extranjero. En 
1980 los clientes nacionales y foráneos realizaron, respectivamente, un 10 y un 26 por ciento menos de estancias que dos años antes.

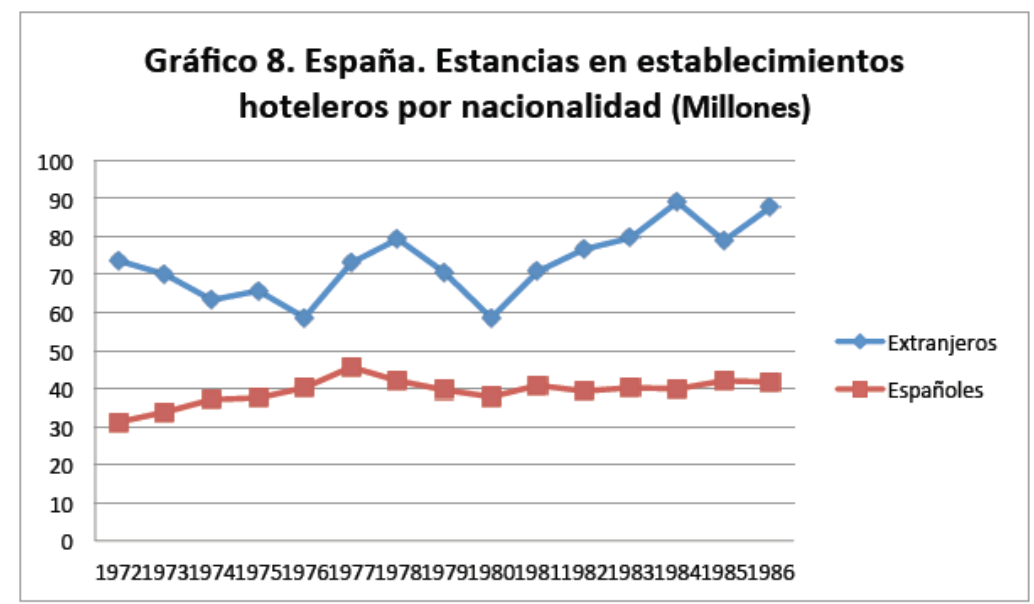

Fuente: INE: Estadística de turismo...., INE: Viajeros en hoteles...., e INE: Movimiento de viajeros.....

El cambio de tendencia, sobre todo por lo que respecta a la clientela extranjera, se produjo a partir de 1981. Desde ese ejercicio y hasta el de 1986 las pernoctaciones totales aumentaron a una tasa media anual del 5 por ciento. Por mercados, fue mucho más dinámico el exterior, que año tras año aumentó a una tasa media del 6'9 por ciento, mientras que el interior se mantuvo bastante estancado. Es evidente que la reactivación económica internacional, un combustible más barato y unos precios más moderados animaron de nuevo el movimiento hotelero extranjero en España. Y que, por el contrario, el elevado desempleo en nuestro país no debió coadyuvar positivamente a que la clientela nacional lo hiciera en la misma medida.

Por otro lado, otro aspecto a destacar en cuanto al movimiento hotelero de los extranjeros en España durante la crisis del petróleo es, en primer lugar, que en las dos etapas más difíciles todos nuestros principales emisores redujeron, en mayor o menor medida, sus estancias, destacando, en este sentido, EEUU-Canadá, los Países Escandinavos y Francia, y, en segundo lugar, que los grandes mercados de la hotelería española, G. Bretaña y Alemania, reforzaron aún más sus cuotas relativas en la década de los años ochenta. Es decir, que a medida que el peso relativo de los clientes procedentes de Norteamérica, Escandinavia y Francia disminuía, el de los británicos y alemanes no paraba de crecer. De hecho, en 1986 ambos mercados aportaban conjuntamente el 44'3 por ciento de las estancias realizadas por clientes extranjeros en nuestros establecimientos hoteleros. O dicho de otra forma, durante la crisis del petróleo no se alivió significativamente la tradicional excesiva dependencia de nuestro turismo respecto a unos pocos mercados emisores.

Y por lo que respecta a los principales destinos españoles por movimiento hotelero, hay que destacar que salvo Gerona, muy dependiente del turismo francés por carretera, el resto solventó bastante bien el primer ciclo negativo merced, sobre todo, 
al mercado nacional. En cambio, tras el segundo shock del precio del petróleo, y la consiguiente caída de las demandas interna y externa, el retroceso del movimiento hotelero fue generalizado en los citados destinos. Así como también fue generalizada la recuperación de la demanda hotelera a lo largo de la década de los ochenta. Por último, señalar que la crisis del petróleo no alteró una de las principales características del turismo español: su excesiva concentración geográfica. De las siete grandes destinos, sólo Madrid, es decir, el interior, y, en menor medida, Barcelona redujeron ligeramente su cuotas de mercado. Por el contrario, mientras Baleares, el primero del ranking con bastante diferencia, y Gerona las mantuvieron, Alicante, Málaga y, sobre todo, Canarias las incrementaron. De tal manera que la cuota conjunta de los citados siete destinos creció entre 1973 y 1986 del 71 al 77 por ciento.

\begin{tabular}{|c|c|c|c|c|c|c|}
\hline Periodo & Alemania & Benelux & Francia & G. Bretaña & $\begin{array}{c}\text { Países Escandi- } \\
\text { navos }\end{array}$ & $\begin{array}{c}\text { EEUU- } \\
\text { Canadá }\end{array}$ \\
\hline $1972-1973$ & 17,5 & 5,3 & 7,3 & 22,2 & 6,2 & 5,1 \\
\hline $1974-1976$ & 17,6 & 5,2 & 6,0 & 18,3 & 5,0 & 3,3 \\
\hline $1977-1978$ & 22,1 & 6,7 & 8,6 & 20,0 & 6,5 & 3,1 \\
\hline $1979-1980$ & 20,0 & 5,7 & 5,8 & 19,5 & 4,2 & 1,8 \\
\hline $1981-1983$ & 21,7 & 6,4 & 6,1 & 27,3 & 3,4 & 2,0 \\
\hline $1984-1986$ & 23,5 & 6,6 & 6,2 & 31,3 & 3,6 & 2,6 \\
\hline
\end{tabular}

Cuadro 8. España. Estancias en establecimientos hoteleros por nacionalidad. Media anual en cada periodo (Millones).

Fuente: INE: Estadística de turismo..., INE: Viajeros en hoteles...., e INE: Movimiento de viajeros.... Elaboración propia.

\begin{tabular}{|c|c|c|c|c|c|c|}
\hline Periodo & Alemania & Benelux & Francia & G. Bretaña & $\begin{array}{c}\text { Países Escan- } \\
\text { dinavos }\end{array}$ & $\begin{array}{c}\text { EEUU- } \\
\text { Canadá }\end{array}$ \\
\hline $1972-1973$ & 16,8 & 5,1 & 7,0 & 21,3 & 6,0 & 4,9 \\
\hline $1974-1976$ & 17,4 & 5,1 & 6,0 & 18,1 & 4,9 & 3,2 \\
\hline $1977-1978$ & 18,3 & 5,5 & 7,1 & 16,6 & 5,4 & 2,6 \\
\hline $1979-1980$ & 19,4 & 5,5 & 5,6 & 18,9 & 4,0 & 1,7 \\
\hline $1981-1983$ & 18,7 & 5,5 & 5,3 & 23,5 & 2,9 & 1,7 \\
\hline $1984-1986$ & 18,6 & 5,2 & 4,9 & 24,7 & 2,8 & 2,0 \\
\hline
\end{tabular}

Cuadro 9. España. Estancias en establecimientos hoteleros por nacionalidad. Cuotas relativas medias en cada periodo (\%).

Fuente: INE: Estadística de turismo...., INE: Viajeros en hoteles...., e INE: Movimiento de viajeros..... Elaboración propia. 


\begin{tabular}{|c|c|c|r|r|r|r|r|}
\hline Periodo & Alicante & Baleares & Barcelona & Canarias & Gerona & Madrid & Málaga \\
\hline 1973 & 5,3 & 31,5 & 6,7 & 9,2 & 6,3 & 8,6 & 6,0 \\
\hline $1974-76$ & 6,4 & 33,1 & 6,6 & 10,4 & 5,3 & 7,9 & 6,3 \\
\hline $1977-78$ & 9,2 & 37,0 & 7,2 & 15,9 & 6,1 & 8,5 & 8,8 \\
\hline $1979-80$ & 7,6 & 33,7 & 5,3 & 13,5 & 4,9 & 7,4 & 6,8 \\
\hline $1981-83$ & 8,9 & 36,1 & 6,9 & 15,5 & 6,6 & 7,7 & 8,4 \\
\hline $1984-86$ & 9,9 & 37,8 & 7,6 & 17,9 & 7,6 & 8,1 & 9,4 \\
\hline
\end{tabular}

Cuadro 10. España. Estancias en establecimientos hoteleros por destinos. Media anual en cada periodo (Millones).

Fuente: INE: Estadística de turismo...., INE: Viajeros en hoteles...., e INE: Movimiento de viajeros..... Elaboración propia.

\begin{tabular}{|c|c|c|r|r|r|r|c|}
\hline Periodo & Alicante & Baleares & Barcelona & Canarias & Gerona & Madrid & Málaga \\
\hline 1973 & 5,1 & 30,3 & 6,4 & 8,9 & 6,1 & 8,3 & 5,8 \\
\hline $1974-76$ & 6,4 & 32,8 & 6,6 & 10,3 & 5,2 & 7,9 & 6,2 \\
\hline $1977-78$ & 7,6 & 30,8 & 6,0 & 13,2 & 5,1 & 7,1 & 7,3 \\
\hline $1979-80$ & 7,3 & 32,5 & 5,1 & 13,1 & 4,8 & 7,2 & 6,6 \\
\hline $1981-83$ & 7,7 & 31,1 & 5,9 & 13,4 & 5,7 & 6,6 & 7,4 \\
\hline $1984-86$ & 7,8 & 29,8 & 6,0 & 14,1 & 6,0 & 6,4 & 7,4 \\
\hline
\end{tabular}

Cuadro 11. España. Estancias en establecimientos hoteleros por destinos. Cuotas relativas medias en cada periodo (\%).

Fuente: INE: Estadistica de turismo..., INE: Viajeros en hoteles...., e INE: Movimiento de viajeros..... Elaboración propia.

\section{Oferta de alojamiento}

A lo largo de los años cincuenta y sesenta, y paralelamente al crecimiento de la demanda turística, en España se había experimentado una muy notable expansión de la oferta de alojamientos turísticos. Buena prueba de ello es que en las dos décadas transcurridas entre 1951 y 1972 nuestro país había triplicado su oferta de hoteles y sextuplicado la capacidad de los mismos. Pero, claro está, no sólo se habían inaugurado hoteles. También se habían abierto al público hostales, pensiones, campamentos y apartamentos, con lo que la oferta española había ascendido a los primeros puestos del ranking europeo. De hecho, y sin contar con los apartamentos, en 1972 la capacidad de acogida ascendía a 866 mil plazas, de las que el 52 por ciento correspondía a los hoteles y el 48 por ciento restante se lo repartían a partes iguales las pensiones y los acampamentos.

Los años dorados del capitalismo habían sido, pues, una etapa en la que ante la creciente, y para algunos inagotable, llegada de turistas, había aumentado el número 
de empresarios, mayoritariamente españoles y hasta entonces vinculados a la agricultura o al comercio, decididos a abandonar, en algunos casos, o diversificar, en otros, sus negocios tradicionales y a invertir en la construcción de establecimientos hoteleros y extrahoteleros, muy especialmente en los dos archipiélagos y en el litoral mediterráneo peninsular. En definitiva, una expansión sin precedentes de nuestros alojamientos turísticos que, además, se había llevado a cabo bajo el férreo control estatal. No hay que olvidar que desde la finalización de la guerra civil la Administración se había reservado el derecho de fijar los precios hoteleros, estableciendo un sistema de máximos y mínimos dentro de los cuales los hoteleros podían moverse. Un privilegio estatal, que había sido una pieza clave de la política turística española a la hora de competir vía precios, y que muy probablemente había desanimado a las grandes cadenas hoteleras internacionales a la hora de invertir en nuestro país.

Pero, tras el boom llegó el estancamiento. La quiebra de la idea de una demanda turística ilimitada, junto con la fuerte elevación de los costes laborales, energéticos, alimentarios y financieros, en un contexto caracterizado por la guerra de precios entre empresas tras la libertad de fijación de los mismos desde septiembre de 1978, afectaron sensiblemente al sector hotelero. A lo largo de la crisis del petróleo, en la que como veremos más adelante la Administración puso en marcha tres planes de modernización hotelera, las inauguraciones fueron escasas, se cerraron algunos establecimientos, se aprobaron regulaciones de empleo y el sector tuvo que hacer frente, sobre todo en los años setenta, a varias huelgas y a un fuerte proceso de descapitalización. Una coyuntura, por lo tanto, nada fácil y que sólo empezó a aliviarse a medida que fue avanzado la primera mitad de los ochenta, con la reactivación de la demanda, un mayor control de la inflación, la recuperación del excedente empresarial en los negocios hoteleros y el aumento de los gastos de mantenimiento y de las inversiones para mejorarlos ${ }^{18}$.

\begin{tabular}{|c|c|c|c|c|}
\hline Oferta Hotelera & 1973 & 1977 & 1981 & 1985 \\
\hline Alojamientos & 9,2 & 9,5 & 9,5 & 9,6 \\
\hline Hoteles & 3,3 & 3,5 & 3,4 & 3,5 \\
\hline Pensiones & 5,9 & 6,0 & 6,1 & 6,1 \\
\hline Plazas & 699,4 & 803,7 & 811,7 & 843,3 \\
\hline Hoteles & 490,9 & 588,8 & 596,7 & $622{ }^{\prime} 4$ \\
\hline Pensiones & 208,5 & 214,9 & 215,0 & 220,9 \\
\hline
\end{tabular}

Cuadro 12. España. Oferta hotelera (Miles).

Fuente: MCT: Anuario...., MIT: Anuario...., у MTTC: Anuario......

De las estadísticas oficiales se desprende que el número total de hoteles y de pensiones, así como la capacidad ofertada en estas últimas, permaneció prácticamente estancado durante el periodo analizado. En cambio, las plazas puestas a disposición de los clientes en

18 CALS, Joan: "Turismo y política turística en España", en Juan VELARDE, José Luis GARCÍA DELGADO y Andrés PEDREÑO (compiladores), El sector terciario de la economía española, Madrid, Colegio de Economistas de Madrid, 1987, pp. 205-217. 
los hoteles aumentaron casi un 27 por ciento. Por lo tanto, parece que durante la crisis del petróleo los empresarios, ante la falta de rentabilidad, dieron en cierta medida la espalda a los hoteles con 1 estrella, los de menor capacidad y los más baratos, y se inclinaron por los catalogados con $4 \mathrm{y}$, sobre todo, con 3 estrellas, los más demandados por los turistas de clase media, nuestros principales clientes. Como consecuencia de ello, entre 1973 y 1985 la cuota conjunta en cuanto a capacidad de ambas categorías creció del 47’2 al 57’6 por ciento, y el tamaño medio de los hoteles españoles de 147 a 176 plazas. En definitiva, hoteles algo más grandes y un mayor peso relativo de la hotelería de categoría media-alta.

\begin{tabular}{|c|c|c|c|c|}
\hline Alojamientos & 1973 & 1977 & 1981 & 1985 \\
\hline Hoteles & & & & \\
\hline $5 *$ & 2,0 & 2,0 & 1,9 & 1,8 \\
\hline $4 *$ & 9,0 & 10,4 & 10,0 & 10,1 \\
\hline $3 *$ & 26,2 & 27,8 & 29,0 & 30,4 \\
\hline $2 *$ & 25,7 & 26,6 & 27,0 & 26,9 \\
\hline $1 *$ & 37,1 & 33,2 & 32,1 & 30,8 \\
\hline Pensiones & & & & \\
\hline $3 *$ & 2,6 & 2,9 & 3,0 & 2,8 \\
\hline $2 *$ & 34,6 & 34,5 & 35,0 & 34,7 \\
\hline $1 *$ & 62,8 & 62,6 & 62,0 & 62,5 \\
\hline
\end{tabular}

Cuadro 13. España. Oferta hotelera por categorías. Cuotas relativas (\%). Fuente: MCT: Anuario ...., MIT: Anuario...., y MTTC: Anuario.... Elaboración propia.

\begin{tabular}{|c|c|c|c|c|}
\hline Plazas & 1973 & 1977 & 1981 & 1985 \\
\hline Hoteles & & & & 4,3 \\
\hline $5 *$ & 4,8 & 4,6 & 4,2 & 17,7 \\
\hline $4 *$ & 14,6 & 17,2 & 17,8 & 39,9 \\
\hline $3^{*}$ & 32,6 & 35,6 & 36,9 & 21,1 \\
\hline $2 *$ & 22,7 & 22,1 & 22,2 & 17,0 \\
\hline $1^{*}$ & 25,3 & 20,5 & 18,9 & \\
\hline Pensiones & & & & 5,5 \\
\hline $3 *$ & 4,5 & 5,0 & 5,2 & 38,7 \\
\hline $2 *$ & 42,7 & 41,8 & 41,5 & 55,8 \\
\hline $1 *$ & 52,8 & 53,2 & 53,3 & \\
\hline
\end{tabular}

Cuadro 14. España. Capacidad hotelera por categorías. Cuotas relativas (\%). Fuente: MCT: Anuario...., MIT: Anuario ...., y MTTC: Anuario.... Elaboración propia. 
En cuanto a la distribución geográfica de nuestra oferta hotelera, la crisis del petróleo no la alteró significativamente. En la práctica totalidad de los principales destinos turísticos el comportamiento del sector fue muy similar al descrito para el conjunto de la nación. Reducción del número de establecimientos hoteleros y crecimiento de la capacidad total hotelera. Estancamiento o disminución de las plazas ofertadas en las pensiones y notable aumento de las ubicadas en los hoteles. Apuesta evidente por la hotelería catalogada con 3 y con 4 estrellas e indudable descenso de la cuota de mercado de los hoteles de 1 estrella, los grandes damnificados de la crisis. Y, por último, un dinamismo en la práctica totalidad de los destinos poderosos no muy diferente al experimentado en otros menos desarrollados. De ahí que, en cuanto a capacidad hotelera, no se produjeran cambios sustanciales en el peso relativo de cada uno de ellos en el total nacional. Sólo Baleares, Gerona, Barcelona y Madrid, los destinos que lideraban el ranking de plazas ofertadas, vieron reducir ligeramente sus cuotas. Por el contrario, en Málaga y, sobre todo, en el archipiélago canario la citada capacidad creció durante la crisis a un ritmo levemente superior a la media nacional. En definitiva, la peso relativo conjunto de los ocho grandes era en 1985, 69 por ciento, apenas cuatro puntos porcentuales menor que la registrada en 1973.

\begin{tabular}{|c|c|c|r|r|r|r|}
\hline & & 1973 & & & 1985 & \\
\hline Destinos & Hoteles & Pensiones & Total & Hoteles & Pensiones & Total \\
\hline Alicante & 208 & 201 & 409 & 218 & 178 & 396 \\
\hline Baleares & 727 & 807 & 1.534 & 730 & 642 & 1.372 \\
\hline Barcelona & 312 & 573 & 885 & 272 & 473 & 745 \\
\hline Gerona & 424 & 534 & 958 & 398 & 496 & 894 \\
\hline Las Palmas & 137 & 108 & 245 & 110 & 60 & 170 \\
\hline Tenerife & 122 & 67 & 189 & 128 & 48 & 176 \\
\hline Madrid & 144 & 665 & 809 & 131 & 670 & 801 \\
\hline Málaga & 155 & 197 & 352 & 155 & 200 & 355 \\
\hline
\end{tabular}

Cuadro 15. España. Oferta hotelera por destino.

Fuente: MCT: Anuario...., MIT: Anuario...., y MTTC: Anuario..... Elaboración propia.

\begin{tabular}{|c|r|r|r|r|r|r|}
\hline & & 1973 & & & 1985 & \\
\hline Destinos & Hoteles & Pensiones & Total & Hoteles & Pensiones & Total \\
\hline Alicante & 33,9 & 7,2 & 41,1 & 44,1 & 6,0 & 50,1 \\
\hline Baleares & 166,6 & 49,5 & 216,1 & 185,0 & 41,9 & 226,9 \\
\hline Barcelona & 39,3 & 20,5 & 59,8 & 43,6 & 18,4 & 62,0 \\
\hline Gerona & 50,1 & 20,9 & 71,0 & 53,1 & 20,9 & 74,0 \\
\hline Las Palmas & 17,9 & 3,5 & 21,4 & 30,1 & 2,5 & 32,6 \\
\hline Tenerife & 24,1 & 2,0 & 26,1 & 37,4 & 1,5 & 38,9 \\
\hline
\end{tabular}




\begin{tabular}{|c|c|c|c|c|c|c|}
\hline Madrid & 27,8 & 15,9 & 43,7 & 32,6 & 15,8 & 48,4 \\
\hline Málaga & 26,4 & 7,3 & 33,7 & 41,3 & 7,7 & 49,0 \\
\hline
\end{tabular}

Cuadro 16. España. Capacidad hotelera por destino (Miles de Plazas).

Fuente: MCT: Anuario...., MIT: Anuario...., y MTTC: Anuario..... Elaboración propia.

\begin{tabular}{|c|c|c|c|c|c|c|c|c|c|c|}
\hline & & & 1973 & & & & & 1985 & & \\
\hline Destinos & $5^{*}$ & $4^{*}$ & $3^{*}$ & $2^{*}$ & $1^{*}$ & $5^{*}$ & $4^{*}$ & $3^{*}$ & $2^{*}$ & $1^{*}$ \\
\hline Alicante & 0,4 & 10,2 & 32,2 & 27,3 & 29,9 & 1,1 & 10,6 & 40,8 & 28,4 & 19,1 \\
\hline Baleares & 1,4 & 7,2 & 37,4 & 27,1 & 26,9 & 0,8 & 10,0 & 47,6 & 24,1 & 17,5 \\
\hline Barcelona & 5,2 & 10,4 & 15,5 & 12,2 & 56,7 & 6,8 & 12,9 & 16,8 & 16,8 & 46,7 \\
\hline Gerona & 1,2 & 4,5 & 29,9 & 33,2 & 31,2 & 0,3 & 5,3 & 38,8 & 29,5 & 26,1 \\
\hline Las Palmas & 12,4 & 29,2 & 44,4 & 11,0 & 3,0 & 10,7 & 30,5 & 40,3 & 16,2 & 2,2 \\
\hline Tenerife & 8,8 & 43,2 & 31,4 & 12,5 & 4,1 & 5,7 & 45,3 & 29,0 & 17,9 & 2,1 \\
\hline Madrid & 24,7 & 29,2 & 27,7 & 10,3 & 8,1 & 24,7 & 38,9 & 26,4 & 5,8 & 4,2 \\
\hline Málaga & 13,4 & 19,2 & 38,4 & 23,1 & 5,9 & 7,7 & 22,8 & 50,8 & 15,4 & 3,3 \\
\hline
\end{tabular}

Cuadro 17. España. Plazas en hoteles por destino. Cuotas relativas (\%).

Fuente: MCT: Anuario...., MIT: Anuario...., y MTTC: Anuario..... Elaboración propia.

\begin{tabular}{|c|c|c|c|c|}
\hline Destinos & 1973 & 1977 & 1981 & 1985 \\
\hline Alicante & 5,9 & 6,3 & 6,1 & 5,9 \\
\hline Baleares & 30,9 & 28,0 & 27,6 & 26,9 \\
\hline Barcelona & 8,5 & 7,9 & 7,8 & 7,3 \\
\hline Gerona & 10,1 & 9,3 & 8,9 & 8,8 \\
\hline Las Palmas & 3,1 & 3,9 & 4,1 & 3,9 \\
\hline Tenerife & 3,7 & 3,8 & 4,4 & 4,6 \\
\hline Madrid & 6,2 & 5,8 & 5,9 & 5,7 \\
\hline Málaga & 4,8 & 5,9 & 5,6 & 5,8 \\
\hline
\end{tabular}

Cuadro 18. España. Capacidad hotelera por destino. Cuotas relativas (\%).

Fuente: MCT: Anuario...., MIT: Anuario..., y MTTC: Anuario..... Elaboración propia.

\begin{tabular}{|c|c|c|c|c|}
\hline Destinos & 1973 & \%/España & 1985 & $\% /$ España \\
\hline Gerona & 54,4 & 25,7 & 70,8 & 18,4 \\
\hline Barcelona & 33,6 & 15,9 & 43,3 & 11,2 \\
\hline Tarragona & 35,0 & 16,5 & 53,6 & 13,9 \\
\hline Alicante & 16,2 & 7,6 & 18,9 & 4,9 \\
\hline Valencia & 10,7 & 5,0 & 16,6 & 4,3 \\
\hline
\end{tabular}




\begin{tabular}{|c|c|c|c|c|}
\hline Castellón & 7,9 & 3,7 & 15,6 & 4,0 \\
\hline Santander & 5,7 & 2,7 & 19,8 & 5,1 \\
\hline Madrid & 5,1 & 2,4 & 14,1 & 3,6 \\
\hline Málaga & 3,7 & 1,7 & 12,0 & 3,1 \\
\hline Oviedo & 2,8 & 1,3 & 14,6 & 3,8 \\
\hline Huelva & 1,4 & 0,6 & 13,5 & 3,5 \\
\hline Total España & 211,6 & & 385,4 & \\
\hline
\end{tabular}

Cuadro 19. España. Plazas en acampamentos por destino (Miles) y cuotas relativas (\%). Fuente: MCT: Anuario...., MIT: Anuario...., y MTTC: Anuario..... Elaboración propia.

A diferencia de lo ocurrido con la oferta hotelera, la extrahotelera parece que continuó creciendo durante la crisis del petróleo ${ }^{19}$. Lamentablemente, no hay datos precisos que permitan cuantificar la magnitud de dicho crecimiento en lo referente a apartamentos, chalets, bungalows, etc. Pero sí existe, en cambio, información cuantitativa oficial sobre los acampamentos. Y, en este caso, la expansión de este tipo de establecimientos, menos costosos a la hora de ponerlos en marcha y especialmente económicos para los clientes, algo a tener muy en cuenta en épocas complicadas, fue indudable a tenor de las estadísticas oficiales. Entre 1973 y 1985 los campamentos pasaron de 511 a 767 y la capacidad ofertada en los mismos aumentó un 82 por ciento. Una expansión, además, que no sólo se dio en las provincias litorales catalanas, los bastiones tradicionales del camping. A lo largo de esta coyuntura dicho sector fue bastante más dinámico en otros destinos marítimos españoles escasamente dotados al inicio de la misma, como Santander, Oviedo, Málaga y Huelva, entre otros.

\section{La política turística: del MIT a la España autonómica}

Desde que se creara en julio de 1951, las competencias turísticas habían estado adscritas en España al MIT ${ }^{20}$. Durante las décadas de 1950 y 1960 las autoridades estatales, cada vez más convencidas de que nuestro país no debía renunciar ni a las divisas proporcionadas por los turistas ni a los efectos positivos que el desarrollo del turismo podía proporcionar a determinadas zonas geográficas, habían fomentado, regulado e intervenido directamente en el sector con el objetivo fundamental de conseguir el mayor crecimiento posible. Entendieron como prioritario el incremento de la llegada de turistas y de la oferta turística del país. Y así fue hasta que a mediados de 1974 la Administración, muy preocupada por la adversa coyuntura turística y por las crecientes críticas hacia algunas consecuencias de su política maximizadora, aprobó como

19 CALS, Joan, "Turismo y política.....p. 211.

20 El MIT fue creado por Decreto Ley de la Presidencia del Gobierno de 19 de julio de 1951. Hasta el verano de 1973 hubo tres ministros: Gabriel Arias Salgado, julio de 1951-julio de 1962; Manuel Fraga Iribarne, julio de 1962-octubre de 1969; y Alfredo Sánchez Bella, octubre de 1969-junio de 1973. 
veremos a continuación un paquete de medidas en el que se contemplaba la contención del crecimiento y un desarrollo turístico más equilibrado ${ }^{21}$.

La verdad es que los últimos cuatro años de vida del MIT se caracterizaron por una notable inestabilidad institucional. Entre el mes de junio de 1973 y el de julio de 1977, cuando se suprimió el MIT, se sucedieron cinco equipos ministeriales ${ }^{22}$. Algo que, naturalmente, en nada benefició al turismo. En una coyuntura marcada por la reducción del número de turistas extranjeros, los vaivenes políticos no ayudaron en absoluto. Si, además, se añaden las crecientes críticas provenientes desde los sectores público y privado sobre la carencia de infraestructuras turísticas, el envejecimiento de parte de la planta hotelera, el mantenimiento de la política de control de precios, el escaso éxito en la ordenación del territorio, los pocos recursos destinados a tareas de promoción, la inexistente coordinación entre los distintos ministerios, la enorme dependencia de nuestro turismo de los turoperadores extranjeros, la falta de atención hacia las empresas de intermediación, la necesidad de una nueva política fiscal sectorial, la creciente destrucción del paisaje o la insuficiente formación profesional, se entenderán mejor las actuaciones del MIT a lo largo del periodo 1973-1977.

El primer paso se produjo en el verano de 1974 al aprobarse un amplio conjunto de medidas con las que se quiso hacer frente a una situación que en aquellos momentos presentaba unas perspectivas nada halagüeñas, y que supuso un cambio muy sensible en la idea que del turismo habían manejado los poderes públicos y en los instrumentos utilizados para su desarrollo. En materia organizativa ${ }^{23}$, lo más significativo fue, junto con el mantenimiento de la Dirección General de Ordenación del Turismo y de la Dirección General de Empresas y Actividades Turísticas, el cambio de nombre del Instituto de Estudios Turísticos, que pasó a denominarse Instituto Español de Turismo $^{24}$ y la creación en el mes de noviembre de la Subsecretaría de Turismo ${ }^{25}$, con el fin de asegurar una acción conjuntada de cuantos organismos se ocuparan de la promoción y gestión del turismo.

Con el paquete de disposiciones que vieron la luz en los meses de julio y agosto de 1974 la Administración le otorgó el carácter de exportadoras a las empresas turísticas, con lo que fueron susceptibles de recibir las ayudas previstas ${ }^{26}$, facilitó las

21 Sobre la política turística del periodo véase VELASCO GONZÁLEZ, María: La politica....; PELLEJERO MARTÍNEZ, Carmelo: "La política turística en la España del siglo XX: una visión general", Historia Contemporánea, $\mathrm{n}^{\circ}$ 25, 2002, pp. 233-265; BAYÓN MARINÉ, Fernando: "Política turística", en Fernando BAYÓN MARINÉ (Director), 50 años del turismo español, Madrid, Centro de Estudios Ramón Areces, 1999, pp. 331-380; y ESTEVE SECALL, Rafael y FUENTES GARCÍA, Rafael: Economías, historia....pp. 215314.

22 En estos cuatro años los máximos responsables del MIT fueron Fernando Liñán y Zofío, junio de 1973-diciembre de 1973; Pío Cabanillas Gallas, enero de 1974-octubre de 1974; León Herrera Esteban, noviembre de 1974-diciembre de 1975; Adolfo Martín Gamero, diciembre de 1975-julio de 1976; y Andrés Reguera Guajardo, julio de 1976-julio de 1977.

23 BOE. Decreto de 9-8-1974.

24 El Instituto de Estudios Turísticos había nacido por Decreto de 5-9-1962 con el objetivo de realizar estudios, investigaciones, dictámenes e informes relacionados con el turismo.

25 Sus máximos responsables fueron José L. López Henares, noviembre de 1974-diciembre de 1975; e Ignacio Aguirre, diciembre de 1975-junio de 1977.

26 BOE. Decretos de 9-8-1974 y Orden de 27-9-1974. 
inversiones en el exterior relacionadas con la actividad turística ${ }^{27}$, reglamentó las actividades de los campamentos y de las agencias de viajes ${ }^{28}$, ordenó la oferta turística y modernizó los establecimientos hoteleros. Fue especialmente relevante el Decreto sobre Medidas de Ordenación de la Oferta Turística ${ }^{29}$. En él se formuló que la política turística debería orientarse hacia la contención del crecimiento y un desarrollo turístico más equilibrado. Parece, pues, que la tradicional idea de crecimiento turístico ilimitado era ya muy cuestionada. Los nuevos objetivos de la política turística serían: 1) acomodar la expansión de la oferta turística en sus aspectos cualitativo, cuantitativo y territorial a las condiciones de la demanda actual y previsible; 2 ) equilibrar el ritmo de nuevas construcciones e instalaciones turísticas al desarrollo de la infraestructura del territorio; 3 ) condicionar las construcciones o instalaciones para que no se produjeran deterioros del medio ambiente ni degradasen la adecuada utilización de los alicientes motivadores del turismo; 4) promover el cambio de las estructuras empresariales para mejorar sus condiciones de rentabilidad, gestión y competitividad en el mercado; 5) fomentar mediante concursos públicos el equipamiento complementario que conviniera a los alojamientos turísticos; y 6) colaborar a la mejora de la infraestructura en lugares declarados de preferente interés turístico.

También fue muy novedoso el I Plan de Modernización Hotelera ${ }^{30}$. Con la intención de mejorar la imagen de buena parte de la oferta hotelera se consideró prioritario adecuar 50.000 plazas a las necesidades de la demanda de entonces y formar y recalificar laboralmente las plantillas relativas a dichas plazas, y que, además, estas acciones se completaran con la dotación de los servicios complementarios a la oferta básica hotelera, la adecuada reclasificación de los hoteles afectados y la reducción temporal de la oferta en aquellas zonas en que hubiera exceso en relación con la demanda. Asimismo, se decidió dar prioridad al crédito hotelero para inversiones de modernización a los edificios con capacidad de alojamiento superior a cien plazas, antigüedad mínima de ocho años, y aquellas industrias hoteleras que promovieran la fusión de varias en una sola explotación de dimensiones más aproximadas a las óptimas de rentabilidad.

Pero, lamentablemente, en los tres años siguientes los nombramientos y ceses en el MIT no contribuyeron a afianzar la nueva tendencia de la política turística. Fue una etapa difícil para el sector, convulsa en los despachos y en la que las medidas más destacadas fueron el Plan de Ayudas a Mesones Turísticos, una acción de fomento centrada en la gastronomía como recurso turístico ${ }^{31}$; las nuevas normativas sobre la ordenación de los apartamentos, villas y bungalows ${ }^{32}$ y sobre reclamaciones de clientes en establecimientos de empresas turísticas ${ }^{33}$; y la declaración de setenta y tres municipios como Territorios de Preferente Uso Turístico ${ }^{34}$. Además, la Administra-

27 BOE. Decreto de 9-8-1974.

28 BOE. Decreto de 20-7-1974 y Orden de 9-8-1974, respectivamente.

29 BOE. Decreto de 9-8-1974.

30 BOE. Decreto 9-8-1974.

31 BOE. Orden de 8-7-1975.

32 BOE. Orden de 14-3-1975.

33 BOE. Decreto de 10-8-1976.

34 BOE. Decreto 28-3-1977. 
ción puso en marcha del II Plan de Modernización Hotelera ${ }^{35}$, que en líneas generales continuó con la filosofía y la forma de actuación del plan previo, pero en el que se estipuló que los criterios preferenciales a la hora de conceder los créditos serían la antigüedad del hotel, los proyectos que implicasen reducción de las habitaciones y aquellos que no habían obtenido beneficios en el plan de modernización anterior. Por último, el MIT decidió emprender el análisis de los recursos y de la oferta turística existente acometiendo la elaboración del inventario turístico. Para ello habría que contar con dos documentos: los Planes de Aprovechamiento de Recursos Turísticos, centrados en provincias determinadas en las que el nivel de desarrollo fuera incipiente, y los Planes de Ordenación de la Oferta Turística, dirigidos a las costas españolas.

Tras la celebración de las elecciones democráticas de junio de 1977, y el triunfo de la Unión de Centro Democrático, se inició una nueva etapa para el turismo. Fueron cinco años en los que la política turística fue bastante continuista en cuanto a los objetivos planteados y a los medios empleados para conseguirlos, pero en la que se produjeron notables cambios derivados, fundamentalmente, de la recuperación de la democracia y la aprobación de la Constitución de 1978.

El día 4 de julio de 1977 desapareció el MIT y se creó la Secretaría de Estado de Turismo en el seno del $\mathrm{MCT}^{36}$, lo que supuso el reconocimiento por parte del Gobierno de la importancia de turismo y significó, en cuanto a recursos, una organización administrativa propia, una asesoría jurídica independiente y una intervención exclusiva. Esta Secretaría de Estado quedó integrada por la Dirección General de Servicios, la Dirección General de Promoción del Turismo y la Dirección General de Empresas y Actividades Turísticas, a la que quedaron adscritos los organismos autónomos Escuela Oficial de Turismo y Administración Turística Española ${ }^{37}$. Además, se reorganizó el Instituto Español de Turismo ${ }^{38}$.

Hasta la aprobación de la Constitución, la Administración reguló el crédito turístico $^{39}$ y aprobó varias normativas sobre cafeterías ${ }^{40}$ y en materia de precios. En este sentido, destaca la Orden de 20 de septiembre de 1978 por la que se determinó que desde ese momento todos los alojamientos turísticos, cualquiera que fuera su clase y categorías, podrían fijar sus precios máximos y mínimos sin más obligación que la de notificar los mismos a la Administración. Se determinó, además, que el precio máximo de alojamiento para cada uno de los tipos de habitación no podría ser superior al 25 por ciento del precio mínimo fijado.

35 BOE. Decreto 16-9-1976.

36 Fue nombrado Ministro José Antonio García Díez. Estuvo en el cargo hasta mayo de 1980, cuando fue sustituido por Luis Gámir. En octubre de ese mismo año, y tras la fusión del MCT con el de Economía, la Secretaría de Estado de Turismo se transfirió al Ministerio de Transporte y Comunicaciones, el cual incorporaría el Turismo a su denominación en marzo de 1981. Esta reorganización supuso la sustitución de Luis Gámir por José L. Álvarez. Aunque por poco tiempo. En la remodelación de diciembre de 1981 Luis Gámir fue nombrado nuevo Ministro de Transporte, Turismo y Comunicaciones. Permaneció en el cargo hasta finales del mes de noviembre de 1982. Al frente de la Secretaría de Estado de Turismo estuvieron Ignacio Aguirre y Eloy Ibáñez.

37 La Escuela Oficial de Turismo había sido creada por Decreto de 7-9-1963. Administración Turística Española nació como organismo autónomo en 1958 al absorber la Red de Establecimientos Turísticos Propiedad del Estado, los Establecimientos Turísticos de Deporte y el Departamento de Rutas Nacionales.

38 BOE. Decreto de 2-6-1978.

39 BOE. Orden de 16-7-1977.

40 BOE. Orden de 28-6-1978. 
Poco tiempo después, el modelo de Estado Autonómico que configuró la Constitución de diciembre exigió cambios institucionales en la política turística. Por un lado, el centralismo uniformador dio paso a un proceso descentralizador a favor de las Comunidades Autónomas que, lamentablemente, estuvo plagado de conflictos de competencias entre aquéllas y la Administración Central que se prolongaron hasta la década de los noventa. Y por otro, los poderes públicos asumieron que en adelante la política en materia turística debería ser bastante menos intervencionista de lo que lo había venido siendo durante el franquismo.

Entre las medidas más relevantes adoptadas durante los años 1979-1982 habría que destacar: el apoyo a la exportación de capitales españoles para efectuar inversiones turísticas en el extranjero ${ }^{41}$; nuevas ordenaciones de centros turísticos de buceo $^{42}$, cafeterías ${ }^{43}$, restaurantes ${ }^{44}$, campamentos de turismo ${ }^{45}$, apartamentos turísticos y viviendas vacacionales ${ }^{46}$, y sobre clasificación de la industria hotelera ${ }^{47}$; regulación de las enseñanzas turísticas especializadas ${ }^{48}$; la nueva normativa sobre crédito turístico ${ }^{49}$ en la que se plantea la restricción máxima a la construcción de nuevas plazas de alojamiento en zonas que se considerasen saturadas, así como el impulso a la modernización y diversificación de la oferta hotelera; aprobación del Reglamento para la ejecución de la Ley de Costas de $1969^{50}$ y del Reglamento de la Ley de Puertos Deportivos ${ }^{51}$; privatización en 1981 de la empresa pública ATESA ${ }^{52}$; elaboración de nuevos planes de aprovechamiento y de ordenación de la oferta turística; establecimiento de las directrices básicas para la declaración de territorios de preferente uso turístico ${ }^{53}$; y aprobación del III Plan de Modernización Hotelera ${ }^{54}$. En este nuevo plan se ampliaron los objetivos de los dos anteriores con los siguientes aspectos: adaptación de las instalaciones a las normativas de seguridad contra incendios; abastecimiento de aguas y saneamiento de las residuales; sanidad y seguridad en las condiciones de trabajo del personal; y renovación de instalaciones y equipos, especialmente las destinadas al ahorro de energía. Unas acciones que tendrían acceso prioritario al crédito hotelero, que financiaría hasta un 70 por ciento del presupuesto de la inversión con una carencia de tres años.

\footnotetext{
41 BOE. Orden 14-9-1979.

42 BOE. Orden de 31-12-1977.

43 BOE. Orden de 28-6-1978.

44 BOE. Orden de10-7-1981.

45 BOE. Decreto de 27-8-1982.

46 BOE. Decreto de 15-10-1982.

47 BOE. Decreto de 15-10-1982

48 BOE. Decreto 14-4-1980.

49 BOE. Orden de 25-10-1979.

50 BOE. Decreto de23-5-1980.

51 BOE. Decreto de 26-9-1980.

52 Empresa pública creada en 1949 en el seno del Instituto Nacional de Industria. Desde entonces se había dedicado a la explotación de circuitos turísticos y excursiones radiales, al alquiler de turismos y de autocares y, desde el año 1956, también a la actividad de agencia de viajes. PELLEJERO MARTÍNEZ, Carmelo: El Instituto Nacional de Industria en el sector turístico, ATESA (1949-1981) y ENTURSA (1963-1986), Málaga, Universidad de Málaga, 2000.

53 BOE. Orden de 13-6-1980.

54 BOE. Decreto de 7-12-1979.
} 
Tras la victoria del Partido Socialista Obrero Español en las elecciones celebradas el 28 de octubre de 1982, la política turística no cambió demasiado ${ }^{55}$. Al menos en la legislatura del primer gobierno, una etapa que se prolongó hasta 1986 y que estuvo marcada por el enfrentamiento competencial en materia turística entre los poderes públicos central y autonómico y por el inicio de la recuperación del sector tras las dificultades padecidas en los años setenta.

La primera medida del nuevo gobierno fue la reorganización del MTTC, lo que supuso la desaparición de la Secretaría de Estado de Turismo y la creación de la Secretaría General de Turismo, equiparada a una subsecretaria y, por tanto, con menor rango administrativo y recursos propios ${ }^{56}$. Sus funciones serían la ejecución y desarrollo de la política turística, la dirección y supervisión de los servicios turísticos de la Administración del Estado y las relativas a la enseñanza de las profesiones turísticas. De ella dependerá una única Dirección General: la de Política Turística. Además, se creó el organismo autónomo de carácter comercial Instituto Nacional de Promoción del Turismo ${ }^{57}$, que más adelante recibirá el nombre de Turespaña, se suprimió el Instituto Español de Turismo, y se reformó la estructura del organismo autónomo Administración Turística Española.

En una de sus primeras comparecencias, en febrero de 1983, la Secretaría General dejó bien claro cuáles serían sus objetivos básicos: coordinación con las Comunidades Autónomas, clarificando el proceso de transferencia; desarrollo de una planificación adecuada, que garantizase diversificación y especialización y conservación de valores paisajísticos, monumentales y culturales; modernización del equipamiento turístico; mejora de la calidad profesional e incremento de la demanda turística interior, manteniendo la demanda exterior ${ }^{58}$. Se consideraba que así se podrían aliviar los principales problemas que afectaban al sector, que no eran otros que la fuerte estacionalidad, el acusado envejecimiento del equipo hotelero, la excesiva homogeneidad de la oferta, la falta de servicios complementarios en los hoteles tradicionales, el crecimiento fuera de control de apartamentos turísticos, la atomización del sector y la falta de diversificación del producto turístico ${ }^{59}$.

Entre las principales disposiciones legislativas del primer gobierno socialista, una etapa en la que culminó el proceso de transferencias en materia de turismo a las Comunidades Autónomas, habría que destacar: ordenación de los establecimientos hoteleros ${ }^{60}$; creación de la categoría Hoteles Recomendados por su Calidad ${ }^{61}$; reconocimiento de que la promoción exterior era competencia del Estado ${ }^{62}$; concesión de ayudas y subvenciones a fondo perdido para el fomento de las ofertas turísticas especializadas, para proyectos de construcción de campamentos, para construcción y

55 En el primer gobierno socialista presidido por Felipe González, Enrique Barón fue designado máximo responsable del MTTC. Se mantuvo en el cargo hasta el mes de julio de 1985, cuando fue sustituido por Abel Caballero. El máximo responsable de la Secretaría General de Turismo fue Ignacio Fuejo.

56 BOE. Decreto de 15-12-1982.

57 BOE. Ley de 30-12-1984.

58 Velasco, p. 250.

59 Velasco, p. 246.

60 BOE. Decreto de 15-6-1983.

61 BOE. Decreto de 27-7-1983.

62 BOE. Decreto de 19-4-1985. 
reforma de establecimientos hoteleros de explotación familiar y para la promoción y comercialización del turismo rural ${ }^{63}$; renovación de las subvenciones a fondo perdido para la promoción y comercialización del turismo rural y aprobación de una línea específica de subvenciones para la mejora, modernización, dotación de instalaciones complementarias e incorporación de nuevas tecnologías en estaciones termales ${ }^{64}$; autorización de operaciones de cambio de divisas a los establecimientos turísticos ${ }^{65}$; y privatización de la empresa pública ENTURSA, que desde el año 1964 se había venía dedicado, con escaso éxito económico, a la construcción y explotación de hoteles y, desde 1975, también al negocio de catering ${ }^{66}$

En definitiva, cuando en 1985 España es admitida en la Comunidad Económica Europea y los síntomas de recuperación de la economía internacional y de nuestro turismo son alentadores, el país carece de una estrategia turística nacional. La Administración Central, tras el traspaso de competencias a las Comunidades Autónomas, ha optado por una cierta dejación de sus funciones. Además, los objetivos y los instrumentos de nuestra política turística son todavía bastante similares a los perseguidos y aplicados con anterioridad a la crisis del petróleo. No obstante, hay más conciencia de que, sin olvidar el aspecto cuantitativo, se debe avanzar en mejoras cualitativas. Algo que se materializará en la década de los noventa. Competitividad, calidad, eficiencia, diversificación, sostenibilidad, se convertirían entonces en conceptos claves de la política turística.

\section{Conclusiones}

¿Cómo evolucionó el sector turístico en España durante la crisis del petróleo? En nuestros país, turísticamente muy dependiente de unos clientes especialmente sensibles a las adversidades económicas y laborales, la evolución de la demanda internacional durante el citado periodo fue creciente pero cíclica. Las dos fases negativas fueron 1974-1976 y 1979-1980. Es decir, unos años marcados por los bruscos encarecimientos del precio del oro negro, el retroceso de la actividad productiva, un alto desempleo y, a nivel interno, además, por una inflación especialmente elevada y la transición política hacia la democracia. Fueron dos etapas en las que las tasas de variación del número de turistas internacionales, así como las del movimiento hotelero, fueron negativas y en las que los más afectados fueron el mercado francés y aquellos viajeros que llegaban por carretera. Pero, afortunadamente, a medida que fue avanzado la primera mitad de la década de 1980 el turismo internacional fijó cada vez más sus ojos en España gracias al abaratamiento del combustible, la recuperación económica y unos precios internos bastante más moderados. Un periodo, este último, caracterizado por la tendencia creciente del flujo turístico hacia España, aunque sin cambios significativos en el ranking de destinos nacionales, así como por un cierto

63 BOE. Orden de 28-2-1984 y 19-7-1984.

64 BOE. Orden de 31-5-1985.

65 Circular del Banco de España de 30-4-1985.

66 PELLEJERO MARTÍNEZ, Carmelo: El Instituto Nacional..... 
mayor dinamismo de los mercados alemán y británico y la cada vez mayor preferencia por el transporte aéreo.

Como es lógico, el sector del alojamiento turístico también se vio afectado en la segunda mitad de los años setenta. Los empresarios tuvieron que hacer frente, en un contexto caracterizado por la guerra de precios entre empresas tras la libertad de fijación de los mismos desde septiembre de 1978, a una sensible caída de la demanda, al envejecimiento de buena parte de la oferta hotelera, a unos costes de explotación al alza, a varias huelgas y a un fuerte proceso de descapitalización. Una coyuntura, por lo tanto, nada fácil y que sólo empezó a aliviarse a medida que fue avanzado la primera mitad de los ochenta, con la reactivación de la demanda, un mayor control de la inflación, la recuperación del excedente empresarial en los negocios hoteleros y el aumento de los gastos de mantenimiento y de las inversiones para mejorarlos. Como consecuencia de todo ello se redujo el número de establecimientos hoteleros pero aumentó la capacidad hotelera total, apostándose sobre todo por los hoteles de 3 y de 4 estrellas en detrimento de los de 1 estrella, apenas hubo modificaciones en cuanto a la concentración geográfica de nuestra oferta hotelera y se incrementaron notablemente los alojamientos extrahoteleros.

Por último, en cuanto a la política turística aplicada por los poderes públicos españoles lo más significativo del periodo es, por un lado, el relajamiento de la Administración Central en cuanto a sus funciones tras el traspaso de competencias a las Comunidades Autónomas por mandato constitucional, y, por otro, un cierto continuismo respecto a la etapa franquista en cuanto a la mayoría de los objetivos perseguidos y los instrumentos aplicados por las autoridades democráticas. No obstante, hay que resaltar que la crisis del petróleo avivó las críticas al modelo de expansión turística experimentado en España en las décadas previas e hizo que se tomara conciencia de que en adelante, y sin olvidar el aspecto cuantitativo, se debía avanzar en mejoras cualitativas. 